UM MUSEU PARA TODOSF MANUAL PARA PROGRAMAS

DE ACESSIBILIDADE
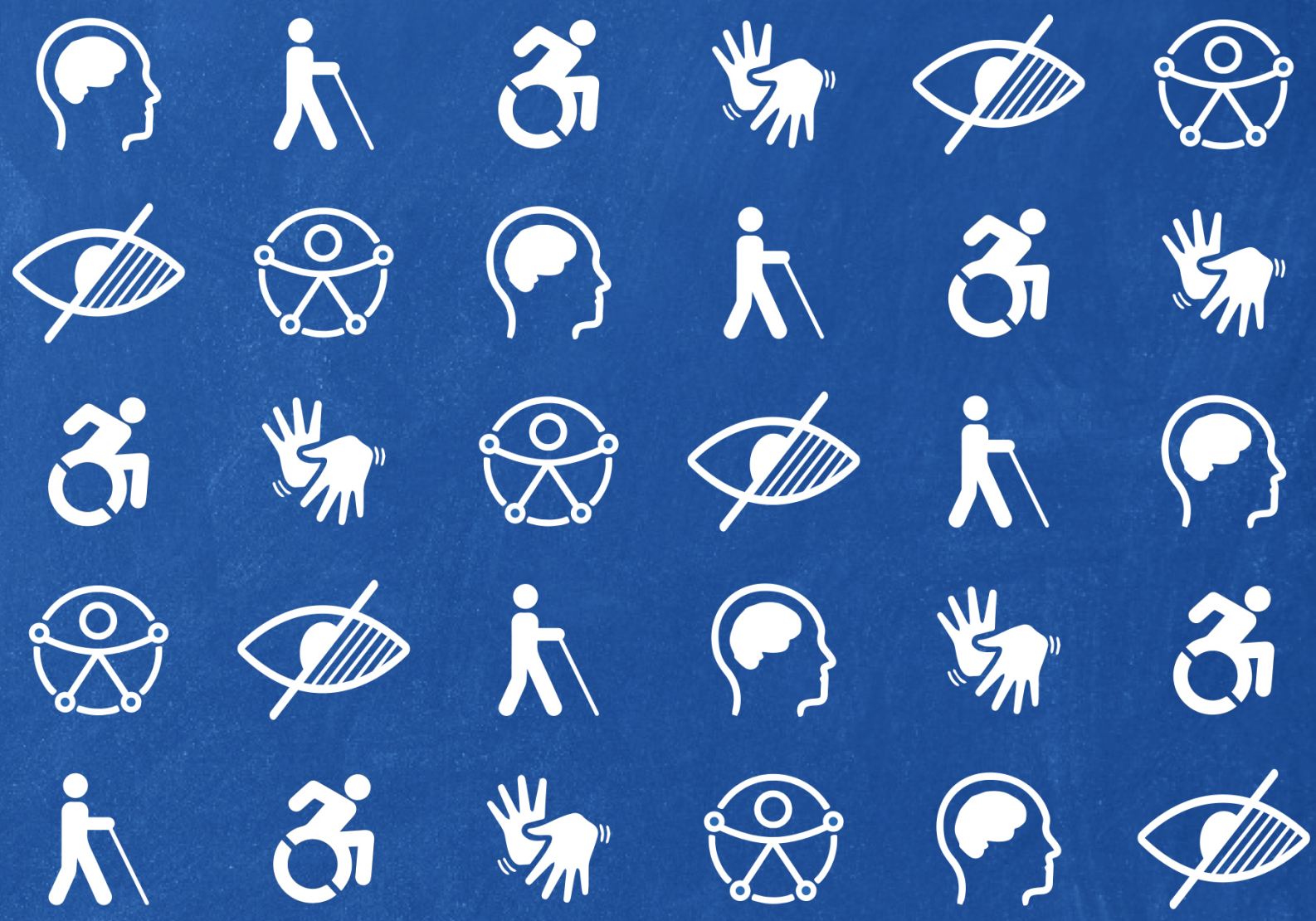
UM MUSEU PARA TODOS: MANUAL PARA PROGRAMAS DE ACESSIBILIDADE 


\section{UM MUSEU PARA TODOS: MANUAL PARA PROGRAMAS DE ACESSIBILIDADE}




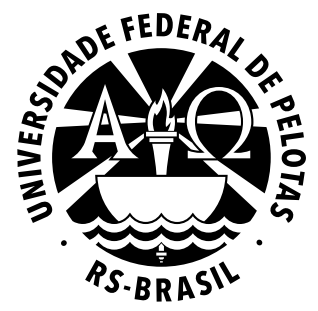

\section{Reitoria}

Reitor: Pedro Rodrigues Curi Hallal

Vice-Reitor: Luis Isaías Centeno do Amaral

Chefe de Gabinete: Tais Ullrich Fonseca

Pró-Reitor de Graduação: Maria de Fátima Cóssio

Pró-Reitor de Pesquisa e Pós-Graduação: Flávio Fernando Demarco

Pró-Reitor de Extensão e Cultura: Francisca Ferreira Michelon

Pró-Reitor de Planejamento e Desenvolvimento: Otávio Martins Peres

Pró-Reitor Administrativo: Ricardo Hartlebem Peter

Pró-Reitor de Infra-estrutura: Julio Carlos Balzano de Mattos

Pró-Reitor de Assuntos Estudantis: Mário Renato de Azevedo Jr.

Pró-Reitor de Gestão Pessoas: Sérgio Batista Christino

\section{Conselho Editorial}

Presidente do Conselho Editorial: Ana da Rosa Bandeira

Representantes das Ciências Agrárias: Guilherme Albuquerque de Oliveira Cavalcanti (TITULAR), Cesar Valmor Rombaldi e Fabrício de Vargas Arigony Braga Representantes da Área das Ciências Exatas e da Terra: Adelir José Strieder (TITULAR), Juliana Pertille da Silva e Daniela Buske

Representantes da Área das Ciências Biológicas: Marla Piumbini Rocha (TITULAR), Rosangela Ferreira Rodrigues e Raquel Ludke

Representantes da Área das Engenharias e Computação: Darci Alberto Gatto (TITULAR) e Rafael Beltrame

Representantes da Área das Ciências da Saúde: Claiton Leoneti Lencina (TITULAR) e Giovanni Felipe Ernst Frizzo

Representantes da Área das Ciências Sociais Aplicadas: Célia Helena Castro Gonsales (TITULAR) e Sylvio Arnoldo Dick Jantzen

Representante da Área das Ciências Humanas: Charles Pereira Pennaforte (TITULAR), Edgar Gandra e Guilherme Camargo Massaú

Representantes da Área das Linguagens e Artes: Josias Pereira da Silva (TITULAR) e Maristani Polidori Zamperetti 
Pró-Reitora de Extensão e Cultura Francisca Ferreira Michelon

Coordenador de Arte e Inclusão João Fernando Igansi Nunes

Coordenadora de Patrimônio Cultural e Comunidade Silvana de Fátima Bojanoski

Coordenador de Extensão e Desenvolvimento Social Felipe Fehlberg Herrmann

Núcleo de Ação e Difusão Cultural Matheus Blaas Bastos

Núcleo de Formação, Registro e Acompanhamento Ana Carolina Oliveira Nogueira Rogéria Aparecida Cruz Guttier

Seção de Integração Universidade e Sociedade Elcio Alteris dos Santos

Seção de Captação e Gestão de Recursos Mateus Schmeckel Mota Elias Lisboa dos Santos

Seção de Mapeamento e Inventário Andrea Lacerda Bachettini

Secretaria

Nádia Najara Kruger Alves

Revisão

Adelino Silveira Soares Junior Luis Gustavo de Pinho Amaral

Projeto gráfico e Diagramação

Natália Marques

Dados de Catalogação na Publicação:

Bibliotecária Leda Lopes - CRB-10/2064

S161m Salasar, Desirée Nobre

Um museu para todos : manual para programa de Acessibilidade / Desirée Nobre Salasar. Pelotas: Ed. da UFPel, 2019

64 p.: il.

ISBN: 9788571929685

1. Museus. 2. Acessibilidade. 3. Ambientes culturais inclusão. I. Título.

CDD 069 


\section{APRESENTAÇÃO}

\section{Museus para todos: é possível!}

Ser possível não é ser fácil. E quando falamos o absoluto imensurável "todos", já anunciamos que a tarefa é das mais difíceis. É verdade que, comumente, evitamos a dificuldade, já que nem sempre estamos prontos para o desafio. Mas do início ao fim, há sempre uma trajetória na qual as pequenas vitórias nos levam adiante.

Assim é o trabalho com acessibilidade. São pequenas vitórias que mudam os princípios de um pensamento que coloca a dificuldade no plano da impossibilidade. Vencer a dificuldade é mudar o mundo, porque é trazer ao campo do possível o que se desenhava, até então, como improvável. É, portanto, mudar uma imagem e, também, aquilo que ela representa.

Os museus, lugares de visitação nos quais o sentido prevalente é o da visão, tornaram-se afeitos ao desafio de receber públicos de pessoas com deficiência visual. Já há experiências antigas, consolidadas e exemplares de exposições inclusivas em museus brasileiros. E conforme o entusiasmo pelos resultados aumenta, outras deficiências vão sendo atendidas em novas propostas. Portanto, são desafios que os museus incorporam com aceitação. No entanto, é sempre bem-vinda a ajuda que pode conduzir a um planejamento realista, mas esperançoso.

É no âmbito do desejo de ajudar que se apresenta essa publicação.

É um texto resultado de uma jornada que se inicia com a participação de Desirée Salasar na Comissão de Apoio ao Núcleo de Acessibilidade e Inclusão da 
UFPel (CONAI), representando, por minha indicação, a Pró-Reitoria de Extensão e Cultura. Como voluntária, Desirée, já vinha trabalhando com a Rede de Museus dessa Pró-Reitoria, exercitando o aprendizado de seis anos no projeto de extensão que coordenei chamado, justamente, "O Museu do Conhecimento para Todos". A Comissão solicitou que as Pró-Reitorias fizessem um Plano de Acessibilidade a ser aplicado com as suas equipes. Desirée atendeu prontamente a demanda e em pouco tempo nos apresentou o seu plano. Nós o saudamos e ela o levou a CONAI. Aprovado, novamente, ele passou a ser desenvolvido, contemplando diversas ações: capacitação aos servidores da Pró-Reitoria, publicações com formatos acessíveis, acessibilidade no sítio eletrônico e redes sociais da PREC, capacitações com a Rede de Museus, entre outras.

Tantas ações foram gerando uma informação sistematizada, voltada a comunicar conteúdos de modo breve, exato e facilmente compreensível e aplicável. Essa informação veio a se apresentar, em dado momento, na forma de uma cartilha sobre acessibilidade atitudinal. Não definia o público, dado o fato de que poderiam ser vários. No entanto, concomitante a esse trabalho, Desirée desenvolvia a proposta de um minicurso voltado para os integrantes da Rede de Museus. O foco era os Programas de Acessibilidade. A consequência de convergir ações, interesses e esforços deu-se pela a ideia de produzir um manual voltado para os museus, inicialmente da UFPel.

Por que não para qualquer museu? Se fosse uma ferramenta que pudesse ser usada em qualquer museu, seria mais útil. Dessa conclusão, gerou-se este livro: sintético, colaborativo, contributivo, simples de ser aplicado e aberto para quem dele queira fazer uso.

De modo geral, a presente publicação expressa a política de extensão hoje praticada pela Pró-Reitoria de Extensão e Cultura da UFPel. Na sua base estão presentes as quatro diretrizes que dimensionam o conceito de extensão universitária no Brasil: a troca de conhecimentos e a atenção para as questões sociais do hoje; a formação cidadã dos nossos estudantes e de nós todos (porque formação não cessa); a produção de mudanças no nosso próprio meio acadêmico e a interdisciplinaridade educativa e social.

É importante que eu conte que Desirée formou-se em Terapia Ocupacional descobrindo como a sua linda profissão poderia ser importante para os museus. 
Que desenvolveu esse tema no seu TCC, hoje referenciado no Curso de Terapia Ocupacional da UFRJ, que apresentou uma proposta de estudo como projeto de dissertação ao Programa de Pós-Graduação em Memória Social e Patrimônio Cultural da UFPel sobre os planos de acessibilidade dos grandes museus do Brasil. Foi selecionada e hoje está desenvolvendo essa pesquisa. Que está ministrando cursos sobre e dentro do tema de acessibilidade em museus e que, portanto, além de exemplificar a desejável formação cidadã, conseguiu conquistar a prática da indissociabilidade entre os conteúdos formativos profissionais, o pensamento investigativo e a práxis da convergência de ambos na realidade social. É, portanto, um exemplo de ouro da formação extensionista.

É um orgulho apresentar esse livro. É uma honra saber que ele exemplifica nossas convicções no campo da extensão. É uma alegria esperançosa e iluminada tê-lo como o primeiro de uma série de outros, cuja finalidade é fazer da Rede de Museus um instrumento que habilitem nossas instituições de conhecimento a conquistarem o estado de "museu para todos".

Que esse manual cumpra a sua missão! 


\section{PREFÁCIO}

Museus e inclusão: palavras que devem caminhar juntas, qualquer que seja a missão das instituições museológicas. Todavia, ao menos no Brasil, a garantia de acessibilidade universal e inclusão de todos nos museus ainda está por ser realizadas.

A obra "Um Museu para todos: Manual para programas de Acessibilidade", em formato de e-book, foi elaborada a partir das experiências de Desirée Salasar em museus portugueses que são exemplos de inclusão. De início, sem maiores pretensões e buscando aproveitar os conhecimentos altamente especializados de Desirée, pensamos em criar um manual para instrumentalizar os museus da UFPel nos processos de elaboração ou revisão dos seus planos museológicos. Afinal, está previsto no Estatuto dos Museus que os projetos e as ações relativas à acessibilidade universal devem constar dos Planos Museológicos. Contudo, a escrita sensível da autora, as imagens cuidadosamente escolhidas, as orientações e sugestões de atividades de sensibilização, tomaram uma dimensão muito maior, como se pode verificar nas próximas páginas.

Mais do que um texto, este é um bom exemplo de trabalho colaborativo, somente possível a partir das generosas relações estabelecidas entre profissionais e instituições e dentro de uma proposta de mobilização em rede. São, ao final, estas conexões horizontais que fortalecem e potencializam ações e conhecimentos em benefício dos nossos museus e coleções.

Este é o espírito que rege as atividades da Rede de Museus da UFPel, que tem como missão unir os museus e processos museológicos para a implantação e 
manutenção de uma política para a área, de forma a desenvolver ações de gestão, valorização do patrimônio museológico e de aproximação com a comunidade. Com esse intuito já fazem parte da Rede algum tempo os museus institucionalizados, como o Museu de Ciências Naturais Carlos Ritter, o Museu de Arte Leopoldo Gotuzzo - MALG e o Museu do Doce.

$E$ também os projetos de extensão relacionados aos museus localizados no entorno de Pelotas: Museu da Colônia Francesa, Museu Grupelli, Museu Histórico de Morro Redondo, mais um centro de memória (Hisales - História da Alfabetização, Leitura, Escrita e dos Livros Escolares), um museu virtual (Museu das Coisas Banais) e ainda o Planetário e o Herbário Pel.

Por trás de cada museu, projeto ou coleção estão professores, pesquisadores, alunos e técnicos, que entendem os espaços museológicos como fundamentais para realizar as suas ações extensionistas e estabelecer um diálogo com as comunidades, quer sejam de visitantes, estudantes, vizinhos ou moradores da cidade.

As equipes que ali trabalham tem agora um valioso guia sobre acessibilidade. Seguimos trabalhando em rede, contando com sensibilidades e produção de conhecimentos que permitam a inclusão de todos dentro dos museus. 


\section{SUMÁRIO}

1 Introdução

2 A evolução da terminologia

3 Programa de acessibilidade em museus

4 Plano de Evacuação de Emergências para Pessoas com Deficiência

4.1 Recomendações para a evacuação de pessoas com deficiência .................................... 20

5 As dimensões da acessibilidade .................................................................................... 22

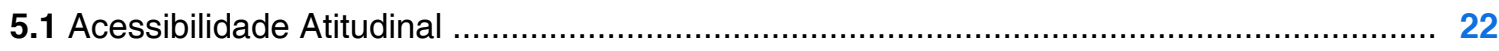

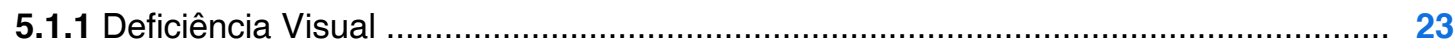

5.1.2 Surdez/Deficiência Auditiva ..................................................................... 24

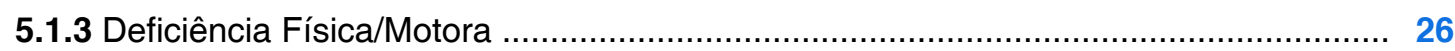

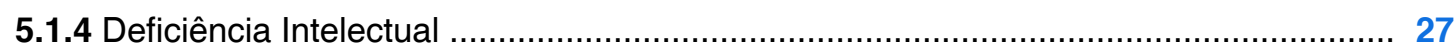

5.2 Acessibilidade Arquitetônica .................................................................................. 28

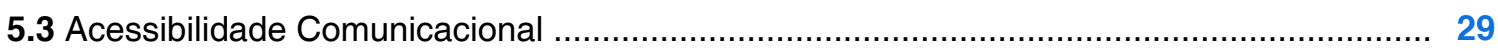

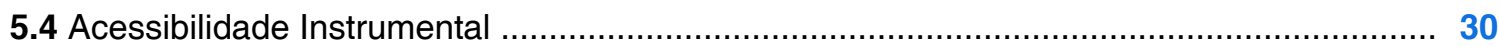

5.5 Acessibilidade Metodológica ........................................................................ 31

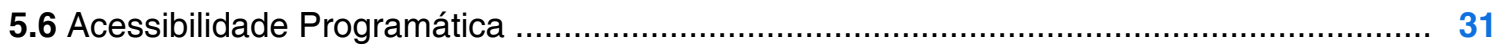

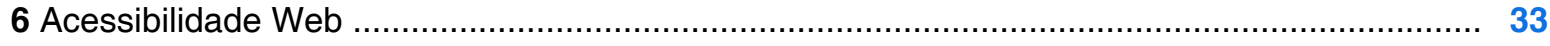

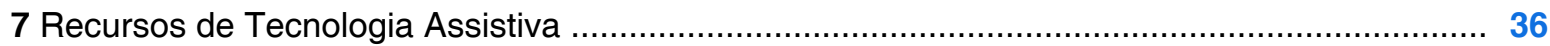

7.1 Acessibilidade Arquitetônica .............................................................................. 36

7.1.1 Acessibilidade arquitetônica para pessoa com deficiência visual ............................ 37

7.1.2 Acessibilidade arquitetônica para surdos e pessoas com deficiência auditiva ........... 39

7.1.3 Acessibilidade arquitetônica para pessoas com mobilidade reduzida e idosos .......... 39 


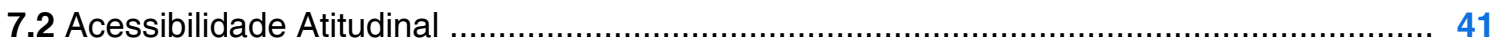

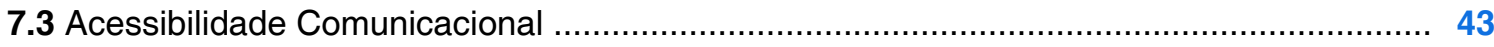

7.3.1 Pessoa com Deficiência visual ....................................................................... 43

7.3.2 Surdos e pessoas com deficiência auditiva ....................................................... 44

7.3.3 Pessoas com mobilidade reduzida/idosos ....................................................... 45

7.3.4 Pessoa com deficiência intelectual ..................................................................... 45

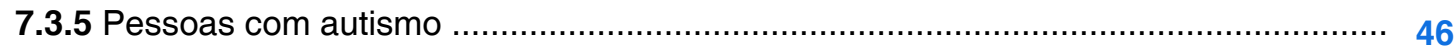

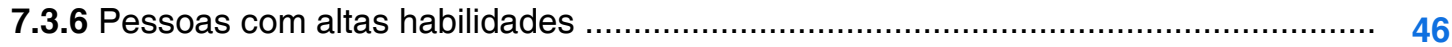

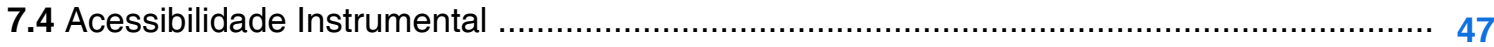

7.4.1 Instrumentos para pessoas com deficiência visual ........................................ 47

7.4.2 Instrumentos para surdos/pessoas com deficiência auditiva ............................. 47

7.4.3 Instrumentos para pessoas com mobilidade reduzida/idosos ............................. 47

7.4.4 Instrumentos para pessoas com deficiência intelectual .................................... 48

7.4.5 Instrumentos para pessoas com autismo .................................................... 48

7.4.6 Instrumentos para pessoas com altas habilidades ...................................... 48

7.5 Acessibilidade Metodológica ......................................................................... 48

8 Alguns recursos de tecnologia assistiva ................................................................. 49

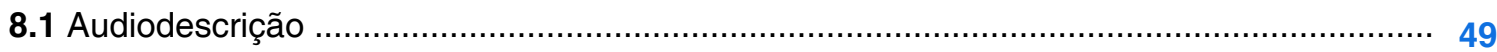

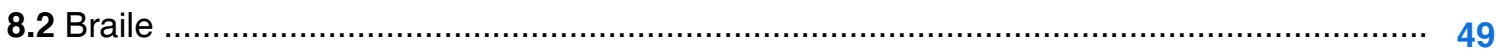

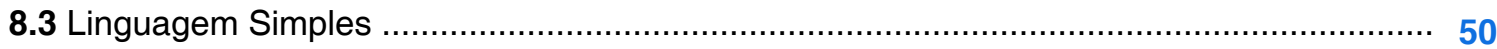

9 A acessibilidade em textos escritos ............................................................................ 51

10 Exemplos de atividades no Setor Educativo do museu ................................................ 52

10.1 Sensibilização para pessoas com deficiência visual .............................................. 53

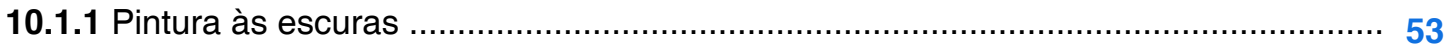

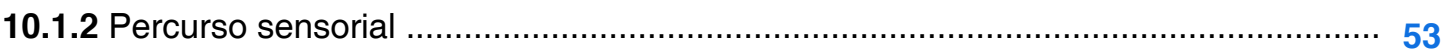

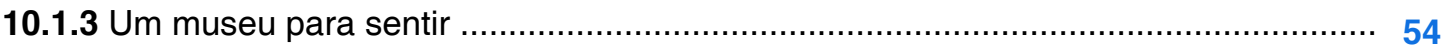

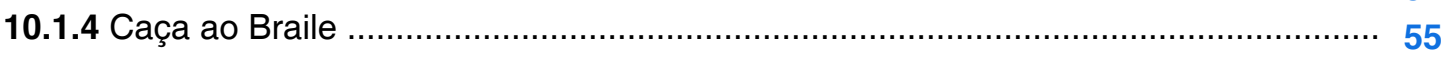

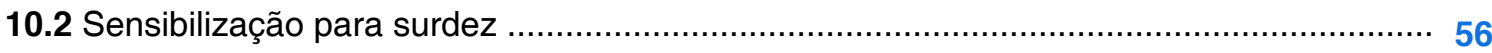

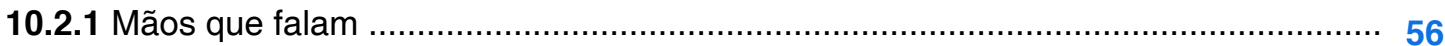

10.3 Sensibilização para pessoas com deficiência intelectual ...................................... 57

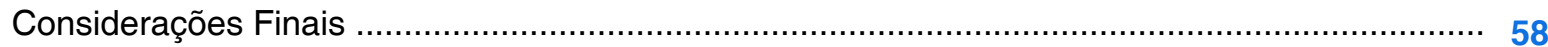

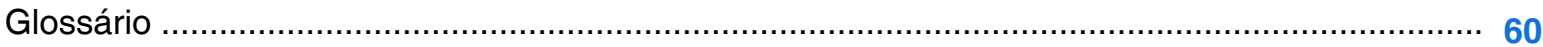

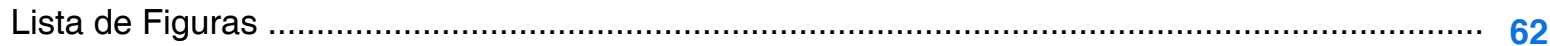

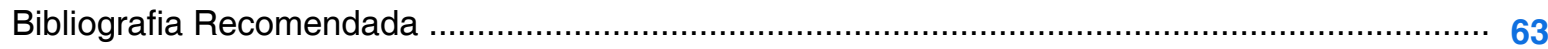




\section{INTRODUÇÃO}

Trabalhar com inclusão em ambientes culturais, vai além de assegurar que os direitos à cultura sejam garantidos e efetivados, é ampliar espaços de fruição para os mais diversos públicos. E quando se fala em fruição, não é somente estar naquele espaço cultural, mas sim poder expressar-se, participar e produzir novos conhecimentos. Dentro deste contexto, acessibilidade e inclusão são dois conceitos fundamentais, distintos, mas que não podem ser dissociados.

A acessibilidade é a condição de acesso aos ambientes, produtos e equipamentos para que pessoas com deficiência, ou com alguma limitação, tenham a garantia de exercer a cidadania com plena igualdade de oportunidades com as demais pessoas. É a garantia que pessoas com deficiência tenham possibilidade de usufruir das experiências que o ambiente oferece, aprender sobre os acervos e ampliar seu repertório de conhecimento cultural.

Incluir é acolher, respeitar, e acima de tudo, entender que ser diferente é o que nos faz semelhantes. Desta forma, para que um espaço seja inclusivo, ele deve proporcionar que o maior número de pessoas (com e sem deficiência) possa desfrutar das experiências ali colocadas. Porém, para que isso aconteça, é necessário que o ambiente possua alguns recursos de tecnologia assistiva, para que pessoas com deficiência possam ter a mesma possibilidade de acesso dos demais visitantes.

Entretanto, nem todos os ambientes que têm acessibilidade são inclusivos. Quando os recursos de tecnologia assistiva estão separados, ou guardados para serem utilizados somente por pessoas com deficiência, isso se caracteriza 
somente como um ambiente que tem recursos acessíveis. A inclusão pressupõe que a pessoa com deficiência não seja segregada, ou seja, que não tenha disponibilizados os recursos de acessibilidade somente para este público-alvo. Portanto, incluir significa entender as potencialidades dos sujeitos frente às suas diversidades e disponibilizar os recursos para todos os públicos em um mesmo espaço. Desta forma, ao disponibilizar os recursos para todos os públicos, pessoas com e sem deficiência têm as mesmas oportunidades de fruição cultural no museu através de experiências multissensoriais.

Assim como as deficiências são diversas, diversos também são os recursos de tecnologia assistiva que dão conta da multiplicidade dos públicos.

Tecnologia assistiva (TA), segundo a Lei Brasileira de Inclusão (Lei 13.146/2015):

\footnotetext{
São os produtos, equipamentos, dispositivos, recursos, metodologias, estratégias, práticas e serviços que objetivem promover a funcionalidade, relacionada à atividade e à participação da pessoa com deficiência ou com mobilidade reduzida, visando à sua autonomia, independência, qualidade de vida e inclusão social (BRASIL, 2015).
}

Assim, entende-se que as tecnologias assistivas são fundamentais para que as pessoas com deficiência tenham autonomia e independência nos museus.

Entretanto, como o próprio conceito apresenta, as práticas e serviços que promovam a funcionalidade da pessoa com deficiência também se caracterizam por tecnologias assistivas.

Desta forma, é importante destacar que, segundo Sassaki (2009), a acessibilidade é composta por seis dimensões, que são: Atitudinal, Arquitetônica, Comunicacional, Instrumental, Metodológica e Programática.

E são estas seis dimensões que estruturam este Manual, voltado para subsidiar discussões sobre a implantação de um programa de acessibilidade em museus. Inicialmente, discute-se brevemente a terminologia, que explicita as mudanças conceituais e de entendimento sobre as pessoas com deficiência nas últimas décadas. Em seguida, aborda-se a questão da acessibilidade na legislação relacionada aos museus. Nos tópicos seguintes trabalha-se com todas as dimensões de acessibilidade, com as tecnologias assistivas possíveis de 
serem implantadas, com recomendações e exemplos de boas práticas dentro dos museus. Por fim, indicam-se exemplos de atividades de sensibilização a serem desenvolvidas nos setores educativos dos museus. Também faz parte do manual o glossário, que tem como objetivo facilitar a assimilação dos principais conceitos sobre acessibilidade. 


\section{A EVOLUÇÃO DA TERMINOLOGIA}

A forma com que a sociedade ocidental enxerga as pessoas com deficiência vêm se modificando muito ao longo do tempo. No Brasil, até o início do século XX, as pessoas com deficiência eram chamadas de inválidos e deveriam permanecer trancafiadas em instituições totais ${ }^{1}$, no qual não era permitida sua saída. As famílias tinham vergonha destas pessoas e as privavam do convívio social.

No período entre as grandes guerras, muitos soldados voltaram às suas pátrias com deficiências adquiridas em batalha. Em decorrência deste fato, neste período, passaram a ser chamados de incapacitados, pois, já não poderiam exercer as mesmas atividades realizadas anteriormente.

A partir da década de 60, com o surgimento das Associações de Pais e Amigos dos Excepcionais (APAE's), tem-se o uso deste termo muito disseminado e com ele uma visão assistencialista das deficiências, que ainda pode ser vista nos dias de hoje. Este assistencialismo decorre do entendimento das pessoas com deficiência como seres especiais e que, portanto, devem ser protegidas de todo o mal. Atualmente, entende-se que esta superproteção acaba por influenciar negativamente no modo como a pessoa com deficiência deve ser estimulada e ter autonomia e independência em sua vida.

Com o crescimento dos movimentos sociais a partir dos anos 80 e também a partir do engajamento das pessoas com deficiência pela luta de seus direitos,

1 Instituições totais eram lugares que confinavam pessoas ao invés de tratarem e estas pessoas institucionalizadas não podiam sair. Eram utilizados para afastar os idosos, as pessoas com deficiência e as pessoas com transtornos mentais do convívio social. 
a Organização das Nações Unidas (ONU) proclamou o Ano Internacional das Pessoas Deficientes em 1981. O objetivo era chamar atenção para a participação plena e igualitária da pessoa com deficiência na sociedade. Então, é neste contexto que pela primeira vez se usou a palavra "pessoa" em frente à deficiência. É a partir deste momento da história que esta parcela da população ganha visibilidade frente à sua existência e aos seus direitos de igualdade de oportunidade com os demais, bem como de reabilitação e prevenção às deficiências adquiridas.

Porém, nas décadas seguintes surgem as nomenclaturas "portador de deficiência" e "portador de necessidades especiais". Estes termos apresentam a deficiência enquanto algo que se "porta" e que pode ser facilmente descartado, ou que é algo temporário. Estes termos sustentam o estigma de que as pessoas carregam uma marca, que é a sua deficiência e acentuam a "necessidade" de estarem segregadas ou excluídas, pois, nesta perspectiva, são dependentes e não têm potencial para terem autonomia em suas escolhas de vida.

O termo "necessidades especiais" advém das práticas educativas, onde as pessoas com deficiência, em determinadas situações, precisam de auxílios diferentes dos utilizados por outras crianças sem deficiência, para seu aprendizado, ou seja, que sempre vai precisar de outra pessoa para realizar suas tarefas. Porém, há de se refletir sobre o termo..., afinal, todos nós aprendemos de uma forma diferente e temos as nossas particularidades. Seguindo esta linha, então todos teriam necessidades especiais?

É a partir de reflexões como esta e do entendimento que a deficiência é uma característica do ser humano e não uma condição portada, que se cunhou o termo "Pessoa com deficiência". Este termo, ao colocar a palavra "pessoa" em primeiro lugar, demonstra que ela possui autonomia para fazer suas escolhas e que a sua deficiência é apenas uma característica e não aquilo que a define.

Desta forma, ao usar a terminologia correta, vai além do "politicamente correto", demonstra respeito pelo outro e por suas lutas. E enxerga no outro uma pessoa que tem potencial e não "um olho gigante que não enxerga", por exemplo. Portanto, não se deve utilizar termos como: "portador de deficiência", "portador de necessidades especiais", "excepcionais", dentre outros similares.

Atualmente a deficiência é considerada apenas mais uma das características da pessoa e não deve ser vista como um "fardo". Assim, o termo correto a utilizar é pessoa com deficiência. 


\section{PROGRAMA DE ACESSIBILIDADE EM MUSEUS}

De acordo com a Lei 11904/2009 (Estatuto dos Museus) e o Decreto 8124/2013, que regulamenta a Lei, no Parágrafo Único do Art. 23: "os projetos e ações relativas à acessibilidade universal nos museus deverão ser explicitados em todos os programas integrantes do inciso IV do caput ou em programa específico resultado de agrupamento ou desmembramento." Segundo o Decreto, todos os museus devem realizar o planejamento anual e dispor do Plano Museológico que pressupõe o tratamento dos recursos para implantar e manter a acessibilidade universal. Os Programas de Acessibilidade se inserem neste contexto.

Desta forma, deve constar no Plano Museológico um documento que apresentará as metas e recursos de tecnologia assistiva que o museu se propõe a implementar. Também deverá conter a sua visão frente à inclusão e a acessibilidade e sua característica como um museu acessível ou um museu inclusivo. Entende-se que museu acessível é aquele que possui alguns recursos de tecnologia assistiva, que estão disponíveis apenas para pessoas com deficiência. Mas o museu inclusivo é aquele que possui e disponibiliza a tecnologia assistiva para todos os seus visitantes, sem distinção de ser ou não pessoa com deficiência.

Recomenda-se que este documento seja elaborado por um profissional da área de acessibilidade, com o apoio da equipe interdisciplinar do museu.

O Programa de Acessibilidade é o documento que respaldará o museu sobre as questões de inclusão cultural da pessoa com deficiência nestes ambientes.

Este documento deverá conter aspectos relacionados às dimensões de acessibilidade que são passíveis de serem implantadas nos museus, conforme se discute nos próximos tópicos. 


\section{PLANO DE EVACUAÇÃO DE EMERGÊNCIA PARA PESSOAS COM DEFICIÊNCIA}

Os museus, em consonância com o artigo 44 da Lei Brasileira de Inclusão, com a NBR9050 (norma de acessibilidade), a NBR 9077 (norma de saídas de emergência em edifícios) e com a Convenção dos Direitos da Pessoa com Deficiência, na qual o Brasil é signatário, devém comprometer-se a tomar medidas que garantam a acessibilidade e total fruição dos seus espaços, garantindo também a segurança das pessoas com deficiência.

A Lei Brasileira de Inclusão (LBI), que dispõe sobre a necessidade de rotas de fugas e saídas de emergência acessíveis, no seu parágrafo $4^{\circ}$, aborda mais especificadamente as questões referentes às situações de risco e de emergências em ambientes culturais públicos. Considerando que são responsáveis pelos seus visitantes, os museus devem estar aptos para realizar os procedimentos de evacuação das pessoas com deficiência em uma situação de emergência.

Os procedimentos a serem seguidos são definidos pelo Plano de Evacuação de Emergência para Pessoas com Deficiência, o qual deve ser elaborado em conformidade com o Plano de Evacuação de Emergência do Museu. Por conta das questões mais específicas sobre deficiência, a participação de um profissional da Acessibilidade é fundamental para a elaboração destes documentos.

É importante ressaltar que depois de elaborado e aprovado, este documento deverá ficar à disposição da equipe do museu para consultas e atualizações. A equipe deve ser continuamente treinada para que não haja dúvidas em frente aos procedimentos de evacuação de emergência para pessoas com deficiência e/ou mobilidade reduzida. Também é de suma importância o treinamento da equipe 
para o reconhecimento dos percursos de evacuação mesmo sem iluminação no ambiente. Além disso, no Plano de Evacuação de Emergência deve constar claramente quem na equipe é responsável pela evacuação das pessoas com deficiência.

Para executar estes procedimentos com eficiência e segurança, a equipe do museu deve ser dividida em dois grupos:

- Equipe de evacuação: são aqueles que estarão aptos a indicar as saídas e auxiliar na evacuação dos visitantes.

- Equipe de contenção: são aquelas que estarão fora do prédio e darão o suporte para as pessoas com deficiência no Ponto de Encontro.

Cabe ressaltar que as pessoas que irão compor cada grupo devem ser sensíveis e atentas às reações e limitações (como pânico, medos, etc.) das pessoas com deficiência que estão sendo evacuadas em uma situação de emergência.

Dentro dos Planos é preciso prever a continuidade da formação destes profissionais e, de tempos em tempos, realizar treinamento dos procedimentos com a equipe, estando atento à rotatividade desta. $E$ também é importante verificar, ao menos uma vez ao ano, as condições do edifício e a eficácia dos procedimentos de emergência.

\subsection{Recomendações para a evacuação de pessoas com deficiência}

É importante que a equipe do museu conheça o número de pessoas com deficiência que estejam no prédio no momento de uma situação de emergência e saibam quais são os procedimentos específicos de evacuação que estas pessoas podem necessitar. Desta forma, as características de cada deficiência também devem ser de conhecimento da equipe responsável pela evacuação, uma vez que diferentes deficiências apresentam características diversas para procedimento de evacuação de emergência. Deve-se ter o cuidado de não priorizar um grupo o qual tenha maior autonomia de deslocamento, para não dificultar a evacuação daqueles que não tem. 
O Elevador, por norma, quando há um alarme de incêndio, vai automaticamente para o térreo e fica desabilitado. Entretanto, caso o responsável pela segurança tenha CERTEZA que o incêndio não traz risco próximo ao elevador, não afeta o percurso e que este facilitará a evacuação de pessoas com deficiência, poderá utilizar a chave de segurança e habilitar o seu uso. Entretanto, cabe ressaltar, que o elevador só poderá ser utilizado em emergências que estejam distantes do mesmo e não ofereçam riscos aos visitantes. $E$ também destacar que é preciso sempre manter a calma e tentar transmiti-la aos visitantes.

A pessoa com deficiência ou com algum tipo de limitação nunca deve ser deixada sozinha, a não ser que seja de sua vontade e que ela tenha total autonomia para a sua evacuação, sem precisar de auxílio de outra pessoa.

Por fim, ressalta-se como fundamental que o Plano de Evacuação de Emergência para Pessoas com Deficiência esteja perfeitamente integrado aos Planos de Emergência dos museus e ao Plano Museológico. 


\section{AS DIMENSÕES DA ACESSIBILIDADE}

\subsection{Acessibilidade Atitudinal}

Destacada pelas pessoas com deficiência como a principal ação de inclusão, a acessibilidade atitudinal se traduz pela eliminação de atitudes, pré-julgamentos, pré-conceitos e estigmas sobre as pessoas com deficiência. Na maioria das vezes, as barreiras atitudinais estão colocadas de forma implícita ou inconsciente, fazendo com que o outro coloque uma barreira sem ao menos dar-se conta do que acabou de fazer. Para tal, é importante que se façam ações de conscientização e sensibilização para a diversidade humana e oficinas de promoção de protagonismo da pessoa com deficiência. Entender que todos são diferentes e possuem características próprias é o primeiro passo para compreender a pluralidade da sociedade em que se vive.

As ações inclusivas são aquelas que beneficiam um público diversificado, tenham deficiência ou não. Porém, em algumas situações, é preciso saber lidar com as diferenças e como agir para incluir, de fato, uma pessoa com deficiência em um ambiente.

O princípio básico da inclusão é a EMPATIA. Isto implica em colocar-se no lugar do outro e não fazer com ele o que você não gostaria que fizessem com você.

É preciso entender que cada pessoa tem um funcionamento diferente, características específicas e que não somos iguais. Somos todos diferentes, porém, temos todos os mesmos direitos.

Este entendimento deve ser a base de todas as discussões sobre a acessibilidade 
e inclusão, devendo ser claramente compreendida pela equipe que trabalha no museu. As especificidades das deficiências são descritas a seguir, acompanhadas de recomendações de boas práticas relacionadas à acessibilidade atitudinal.

\subsubsection{Deficiência Visual}

Segundo o Censo de 2010, a deficiência visual é a principal deficiência dos brasileiros. Porém, há muitos mitos relacionados a ela, sendo assim, é importante explanar neste documento o que não é verídico.

Um deles diz respeito à deficiência visual ser caracterizada apenas pelas pessoas cegas. É preciso ter em mente que existem diversos tipos de deficiência visual, divididas em dois tipos: cegueira e baixa visão, sendo que ambas podem ser congênitas (onde a pessoa já nasce com a deficiência) ou adquiridas.

A origem das deficiências visuais é diversificada, tanto em relação à cegueira quanto à baixa visão. São alguns exemplos: catarata congênita, retinoblastoma, glaucoma, degeneração macular relacionada à idade, entre muitas outras.

Entretanto, a origem da deficiência não influencia em nada na convivência social da pessoa, uma vez que ela somente será influenciada pelos estímulos e pelas vivências que teve durante a sua vida.

Assim, é importante lembrar que saber a causa da deficiência não é uma informação significativa, porque há possibilidade de, por exemplo, existirem duas pessoas cegas congênitas em decorrência de uma catarata, onde uma será completamente autônoma e independente e a outra vai depender de um cuidador para todas as suas atividades.

Desta forma, é preciso entender que cada pessoa é singular e que não será a deficiência dela que determinará que tipo de recurso deverá ser utilizado.

Atualmente há um crescente movimento para dar visibilidade às pessoas com baixa visão através da cor da bengala utilizada. Assim, ao encontrar uma pessoa com uma bengala verde circulando no museu ou em qualquer outro lugar, identifique-a como uma pessoa com baixa visão e não como uma pessoa cega. 


\section{BOAS PRÁTICAS PARA INTERAÇÃO COM PESSOAS COM DEFICIÊNCIA VISUAL}

1. Fale sempre diretamente com a pessoa e não com o seu acompanhante;

2. Não grite ou a infantilize;

3. Pergunte sempre se a pessoa quer a sua ajuda. Não se sinta constrangido se não souber ajudá-la. Pergunte como fazer;

4. Pergunte se ela deseja ser conduzida, não a puxe pelo braço e saia caminhando;

5. Caso ela queira auxílio, ofereça seu braço que ela pegará em seu cotovelo (ou ombro);

6. Use indicações verbais de localização, como direita, esquerda, acima, abaixo;

7. Apresente o espaço/ambiente para ela. (É amplo, pequeno, aproximadamente quantos metros?);

8. Avise-a dos obstáculos (degraus, portas, curvas, desníveis...);

9. Nunca brinque ou toque em um cão-guia! Ele está trabalhando!

\subsubsection{Surdez/Deficiência Auditiva}

Aqui existem duas nomenclaturas que se confundem, mas que diferem sob o ponto de vista socioantropológico: pessoas surdas e pessoas com deficiência auditiva.

As pessoas surdas são aquelas que pertencem à Comunidade Surda e que utilizam a Língua Brasileira de Sinais (Libras) como forma de comunicação. São consideradas uma minoria linguística no Brasil, mas possuem uma identidade e uma cultura própria que provém da especificidade de sua língua ser vísuoespacial. É importante ressaltar que libras é uma língua e não uma linguagem e que ela não é universal, assim como as línguas orais diferem de um país para outro, as línguas de sinais também seguem esta lógica. 
Já a deficiência auditiva é caracterizada sob o ponto de vista clínico da perda auditiva. Ou seja, são aquelas pessoas que não são usuárias de libras e que fazem leitura labial ou que utilizam o implante coclear². Geralmente são oralizadas e verbalizam suas falas.

\section{BOAS PRÁTICAS PARA INTERAÇÃO COM SURDOS}

1. Acene ou toque levemente na pessoa quando quiser chamá-la;

2. Caso você não saiba língua de sinais, a comunicação com uma pessoa surda será pela escrita. Escreva em um papel, celular... Mas não deixe de se comunicar pelo fato de não saber a língua do outro;

3. Se tiver interesse e possibilidade, peça para o Surdo ensinar alguns sinais para você se comunicar com ele;

4. Caso haja um Intérprete de Libras, dirija-se à pessoa surda e não ao intérprete.

\section{BOAS PRÁTICAS PARA INTERAÇÃO COM PESSOAS COM DEFICIÊNCIA AUDITIVA}

1. Acene ou toque levemente na pessoa quando quiser chamá-la;

2. Posicione-se sempre em frente a ela e mantenha contato visual para que saiba que está mantendo uma conversa;

3. Não fique contra a luz e/ou com objeto na frente da boca. Isto dificulta a comunicação. Procure ficar a favor da luz para facilitar a leitura labial.

2 Dispositivo médico eletrônico para pessoas com perda auditiva de grau severo a profundo. $\mathrm{O}$ implante coclear envia estímulos elétricos diretamente ao nervo auditivo, transformando-os em som. 


\subsubsection{Deficiência Física/Motora}

Assim como a deficiência visual, as deficiências físicas e motoras também são diversificadas e podem ser tanto congênitas, adquiridas ou até mesmo degenerativas. Podem ser decorrentes de causas peri ou pós-natal ${ }^{3}$, de acidentes, etc, e podem ocorrer nas mais diversas faixas etárias, com exceção as que ocorrem no nascimento. Esses são alguns exemplos de deficiência físicas: amputações, má formação de membros, paraplegias, etc.

Algumas deficiências motoras podem ser em decorrência de paralisia cerebral, síndromes genéticas, entre outros. Porém, mantenha em mente que nem sempre a deficiência física ou a mobilidade reduzida estará visível. Por isso não faça préjulgamentos sem antes conhecer ou perguntar à pessoa. Por vezes a pessoa está em uma cadeira de rodas porque não pode andar por longas distâncias, mas não quer dizer que não consiga ficar em pé.

\section{BOAS PRÁTICAS PARA INTERAÇÃO COM PESSOAS COM DEFICIÊNCIA FÍSICAS / MOTORAS}

1. A cadeira de rodas é uma extensão do corpo da pessoa, não empurre sem avisar antes;

2. Se a pessoa recusar ajuda para empurrar a cadeira de rodas, não se ofenda;

3. Se você vai falar durante um tempo para uma pessoa cadeirante, procure sentar e ficar na altura dela;

4. Mantenha muletas e bengalas sempre próximas da pessoa;

5. Em caso de dificuldades para subir ou descer escadas, pergunte como pode ajudá-la.

3 Peri natal - antes do parto. Pós-natal - pós-parto. 


\subsubsection{Deficiência Intelectual}

As deficiências intelectuais também são diversas e são divididas em três níveis: leve, moderada e severa. Em sua grande maioria são decorrências de causas peri ou pós-natal ou de síndromes genéticas. O funcionamento cognitivo destas pessoas apresenta limitações em duas ou mais áreas das habilidades adaptativas, ou seja: comunicação, cuidado pessoal, saúde, segurança, habilidades sociais entre outras. A principal característica é a dificuldade de raciocínio e compreensão. Porém, tenha em mente que pessoas com deficiência intelectual, no geral, não possuem limitações de crescimento. Desta forma, se a pessoa já for adulta, atenção para não tratá-la como uma criança! Considere que os conceitos abstratos são mais difíceis para serem entendidos. Por isso, em determinadas situações, será mais eficaz mostrar um objeto concreto ao invés de só falar dele.

\section{BOAS PRÁTICAS PARA INTERAÇÃO COM PESSOAS COM DEFICIÊNCIA INTELLECTUAL}

1. Não infantilize a pessoa com deficiência intelectual, trate-a como trataria uma pessoa sem deficiência com a mesma idade;

2. Quando tiver uma explicação muito complexa, procure usar pequenas frases, claras e concisas;

3. Use e abuse de imagens, elas auxiliam no entendimento de coisas abstratas;

4. Sempre que possível, mostre objetos dos quais você está falando para que possam ser tocados.

Estas práticas são apenas algumas sugestões relacionadas à acessibilidade atitudinal. Servem para entender um pouco mais sobre questões ligadas às deficiências. Porém, não são uma verdade absoluta, cada pessoa é única e, como já foi dito anteriormente, o tipo de deficiência não vai definir como será a vida da pessoa. Tudo dependerá de como ela foi estimulada e das experiências de vida que ela teve. 


\subsection{Acessibilidade Arquitetônica}

A acessibilidade arquitetônica é a mais aparente para as pessoas, e aquela que é sempre citada, diz respeito às adaptações/construções estruturais nos ambientes. Entretanto, é importante destacar que ela garante apenas o acesso físico ao ambiente.

Desta forma, é relevante que o museu possua espaços amplos, sem obstáculos para livre fruição, sem desníveis ou degraus entre os ambientes. Os mobiliários devem ser rebaixados para que pessoas em cadeiras de rodas tenham acesso aos objetos ali expostos. O piso podotátil dá a garantia para que pessoas com deficiência visual possam ter autonomia no ambiente.

É relevante destacar que a acessibilidade arquitetônica também deve englobar um percurso acessível ${ }^{4}$ para que os visitantes possam chegar até o museu com o mínimo de barreiras possíveis.

As Figuras 1 e 2 mostram dois exemplos de acessibilidade arquitetônica do Museu do Doce da Universidade Federal de Pelotas (UFPel), onde se pode ver os mobiliários rebaixados e espaços amplos que facilitam a fruição e circulação do visitante.

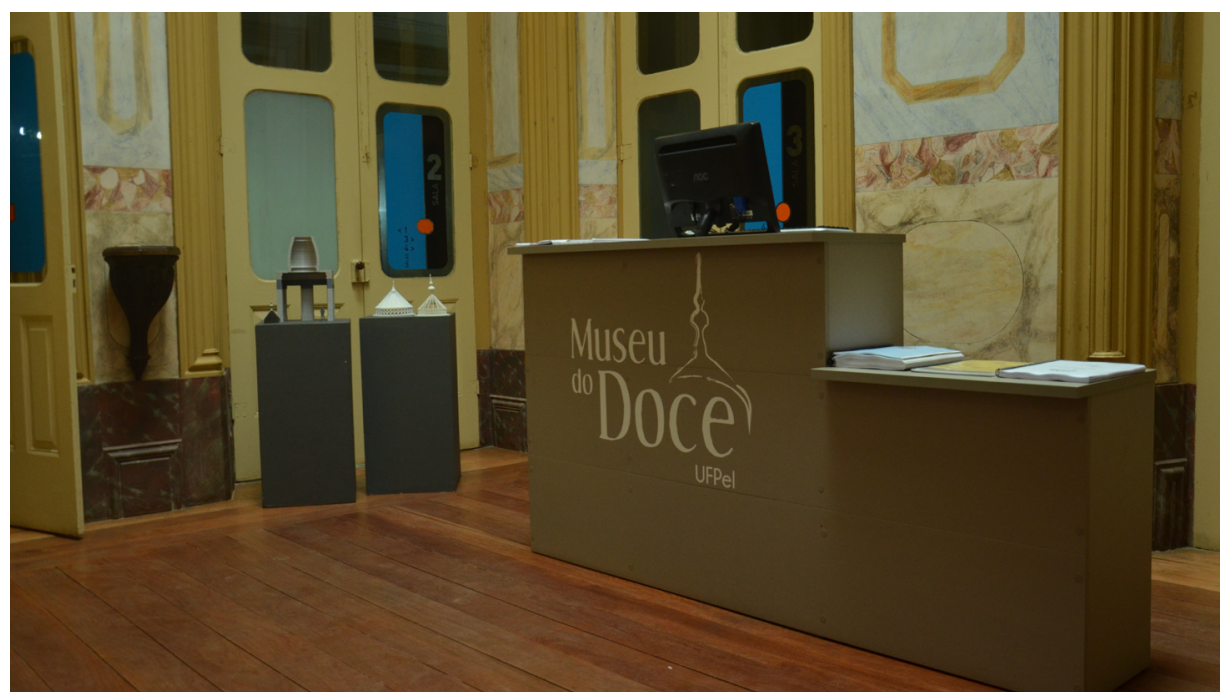

Figura 1: Espaço amplo e mobiliário rebaixado no Museu do Doce. Fonte: Acervo da Rede de Museus da UFPel.

4 Para entender melhor sobre percurso acessível, vide NBR()\%). 


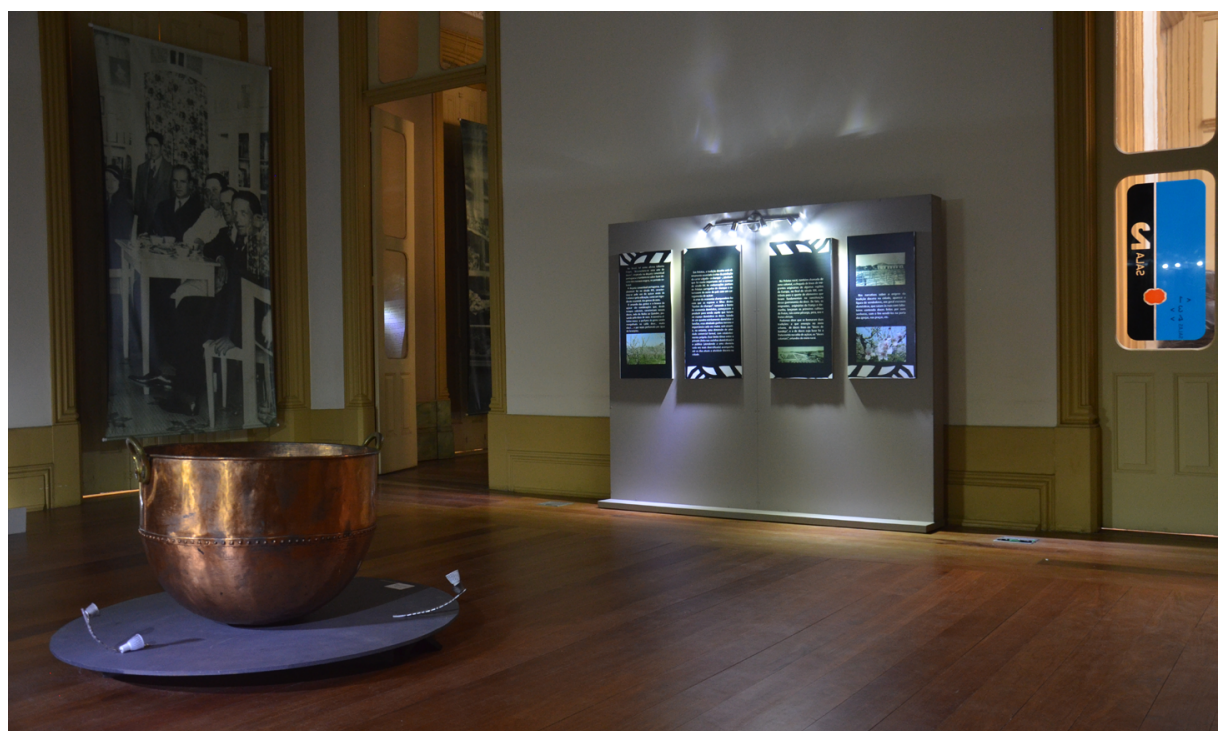

Figura 2: Espaço amplo no Museu do Doce. Fonte: Acervo da Rede de Museus da UFPel.

\subsection{Acessibilidade Comunicacional}

A base da transmissão de mensagens (entre os indivíduos e entre indivíduos e ambientes) é a comunicação. Os museus são ambientes essencialmente comunicativos, que buscam, através de seu acervo, dialogar com seus visitantes.

Entretanto, é importante estar atento às estratégias comunicacionais adotadas pelos museus para dialogar com seus públicos.

Um museu, que tem como missão ou objetivo previsto no Plano Museológico receber públicos diversos ou não restringir o acesso da população que pretende atingir, deve estar ciente que isto pressupõe a inclusão e recepção de pessoas com deficiência. Para tal, o museu deve estar apto para estabelecer comunicação com esta parcela da população e, para isto, deve estar familiarizado com os recursos de tecnologia assistiva. Destaca-se que as tecnologias assistivas que efetivam a comunicação em museus variam de acordo com os tipos de deficiência que pretendem incluir.

A Figura 3 mostra o exemplo de um recurso existente no Memorial do Anglo da Universidade Federal de Pelotas (UFPel), o qual auxilia na acessibilidade 
comunicacional. Trata-se de um esquema tátil ${ }^{5}$ usado para explicar os planos de uma fotografia.

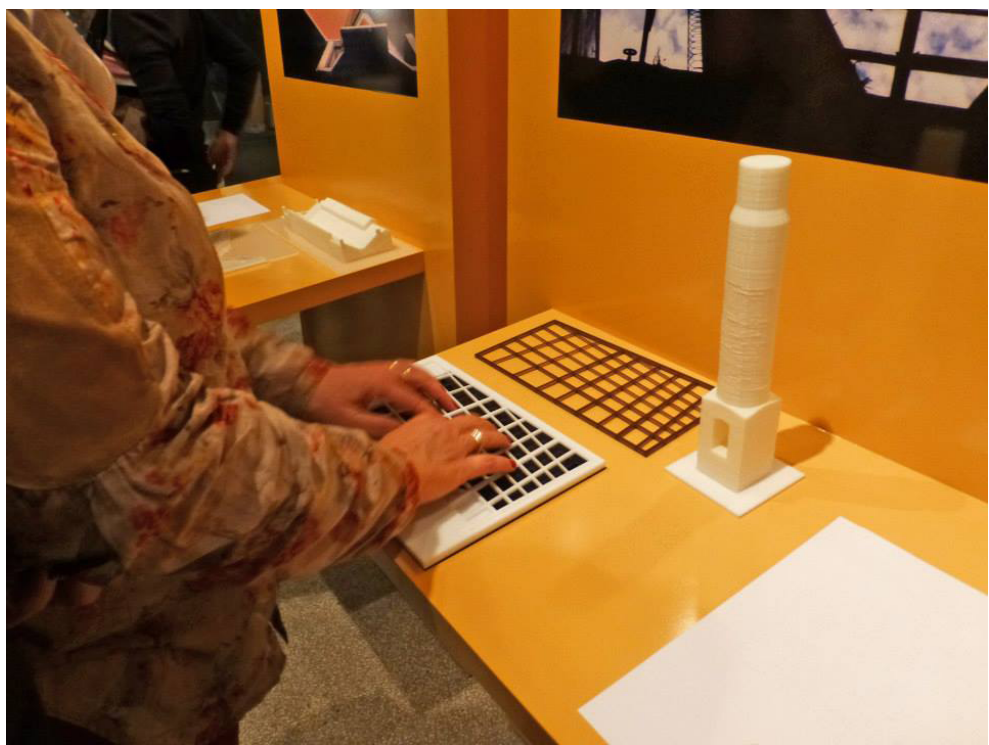

Figura 3: Esquema tátil que auxilia o entendimento da fotografia no Memorial do Anglo. Fonte: Arquivo pessoal da autora

\subsection{Acessibilidade Instrumental}

A acessibilidade instrumental diz respeito à inexistência de barreiras nos instrumentos, utensílios e ferramentas de estudo, de trabalho, de lazer ou recreação. Ou seja, traduzindo para os museus, são as adaptações de instrumentos que são utilizados para garantia de acesso ao acervo e ao ambiente. São exemplos de acessibilidade instrumental: o uso de audioguias, equipamentos e materiais utilizados no serviço educativo para visitas mediadas.

É importante que, ao preparar uma visita guiada para um público com deficiência, os servidores do museu estejam aptos a utilizar instrumentos que auxiliem a inclusão destes visitantes neste ambiente.

A Figura 4 mostra um exemplo do Memorial do Anglo da Universidade Federal de Pelotas (UFPel), onde o audioguia é o recurso de acessibilidade instrumental

5 Ver esquema tátil no glossário. 
utilizado para comunicar uma fotografia através da audiodescrição.

Destaca-se a necessidade de optar por instrumentos de uso intuitivo, com uso simples. Portanto, quanto menos botões, melhor.

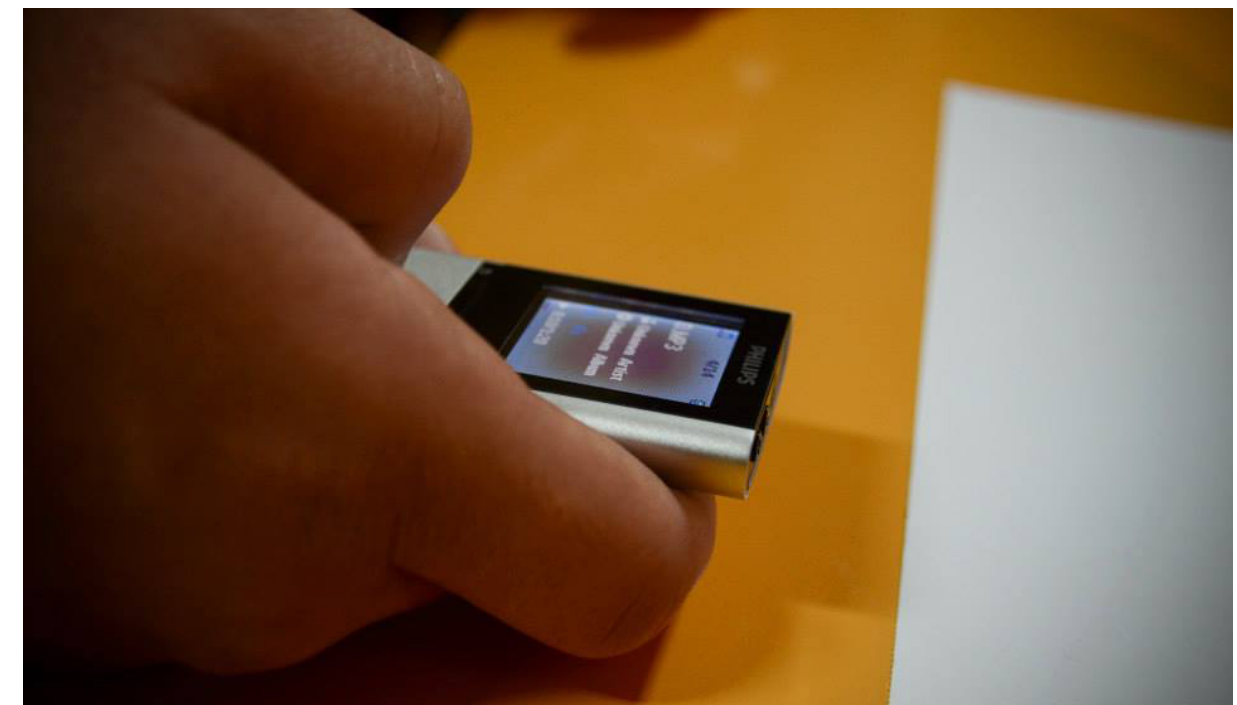

Figura 4: Aparelho de mp3 utilizado como instrumento para audiodescrição no Memorial do Anglo. Fonte: Roberta Freitas

\subsection{Acessibilidade Metodológica}

Os métodos são de suma relevância para que a inclusão seja efetiva. Assim, faz-se necessário conhecer o público que será recebido, para que se pense acerca de recursos metodológicos que darão conta da comunicação entre museu e visitante. São exemplos de acessibilidade metodológica: visitas mediadas, jogos, pranchas de comunicação alternativa, adaptações do discurso expositivo do museu, entre outros.

\subsection{Acessibilidade Programática}

Caracterizada como a acessibilidade que diz respeito às legislações e normativas visando à eliminação de barreiras dos direitos da pessoa com 
deficiência nos mais diversos contextos. Nos ambientes museais destaca-se a importância do museu ter, junto ao seu Plano Museológico, um Programa de Acessibilidade, conforme já foi destacado anteriormente.

Para além das seis dimensões de acessibilidade descritas acima, atualmente há mais uma em discussão que será apresentada abaixo. 


\section{ACESSIBILIDADE NA WEB}

A expressão acessibilidade na web refere-se à prática inclusiva de fazer websites que possam ser utilizados por todas as pessoas, que tenham ou não deficiência. Quando os sites são corretamente concebidos, desenvolvidos e editados, todos os usuários podem ter igual acesso à informação.

Desta forma, quando o texto e as imagens são grandes e/ou passíveis de ampliação, a leitura e compreensão do conteúdo torna-se mais fácil para os usuários com baixa visão. Links sublinhados (ou diferenciados de outra maneira) e coloridos garantem que usuários daltônicos sejam capazes de diferenciá-los.

Links e áreas clicáveis com fontes grandes auxiliam os usuários que não podem controlar um mouse com precisão. Quando as páginas são codificadas para os usuários poderem navegar utilizando somente o teclado ou uma única tecla de acesso, é uma importante ajuda para aqueles que não podem utilizar um mouse ou até mesmo um teclado padrão. Vídeos legendados ou disponibilizados com versões em língua de sinais garantem a acessibilidade para pessoas surdas ou com dificuldade de audição. Conteúdo disponibilizado em linguagem simples e ilustrado com gráficos e animações instrucionais é funcional para pessoas com dislexia e dificuldades de aprendizagem, pois, facilita a compreensão do conteúdo.

Sites corretamente construídos e mantidos atendem à necessidade de todos esses usuários, sem causar impacto na usabilidade do site para os demais usuários.

$\mathrm{Na}$ Internet o termo acessibilidade referi-se também as recomendações do validador online $\mathrm{W} 3 \mathrm{C}$, que visam permitir que todos possam ter acesso aos websites, independente de terem alguma deficiência ou não. As recomendações 
abordam desde o tipo de fonte a ser usado, bem como seu tamanho e cor, de acordo com as necessidades do usuário, até as recomendações relativas ao código (HTML e CSS, por exemplo). Isso ajuda na melhoria da disponibilização da informação, podendo assim garantir que o site do museu chegue a todos de forma simples e precisa.

No caso de um museu virtual ou do museu ter um site, deve-se considerar as barreiras de comunicação deste frente à pessoa com deficiência. Para tal, recomenda-se também seguir a cartilha de acessibilidade dos sites do governo ${ }^{6}$.

A Figura 5 mostra uma imagem do site da Pró-Reitoria de Extensão e Cultura da Universidade Federal de Pelotas (UFPel), que segue as normativas de acessibilidade dos sítios governamentais.

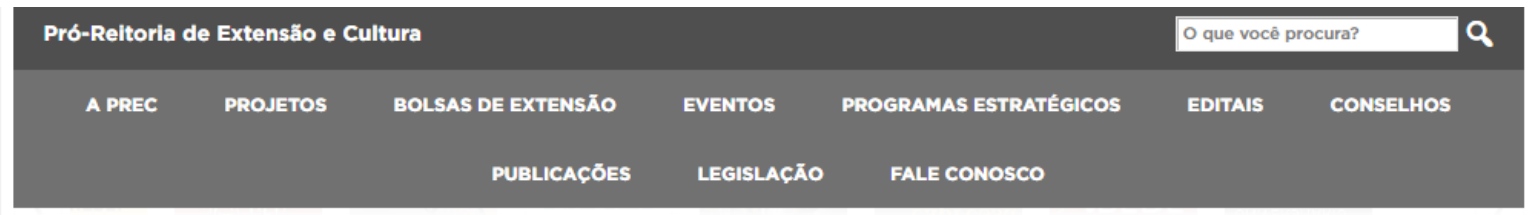

NOTICIAS

Jantar de Posse da Patronagem do C.T.G. "Os Carreteiros" 30/07/2018 18:29

A Pró-Reitoria de Extensão e Cultura informa que no dia $1^{\circ}$ de setembro será realizado o Jantar de Posse da Patronagem do C.T.G. "Os Carreteiros", abrindo a Semana Farroupilha. Os ingressos podem ser adquiridos com a direção da FAEM ou na PREC (anglo).

O jantar será realizado a partir das $20 \mathrm{~h}$. O cardápio será galeto, arroz e saladas (de batata e verdes). $\mathrm{O}$ baile será a partir das 22hoo, por conta do Grupo Querência.

Dia: $1^{\circ}$ de setembro.

Local: C.T.G. "Os Carreteiros"

Ingressos: Com jantar: 25,00 reais. Sem jantar: 20,00 reais.

\section{Universidade Aberta à Terceira Idade convida para oficina} 27/07/2018 13:36

Figura 5: Tela principal do site da Pró-Reitoria de Extensão e Cultura - UFPel. Fonte: PREC

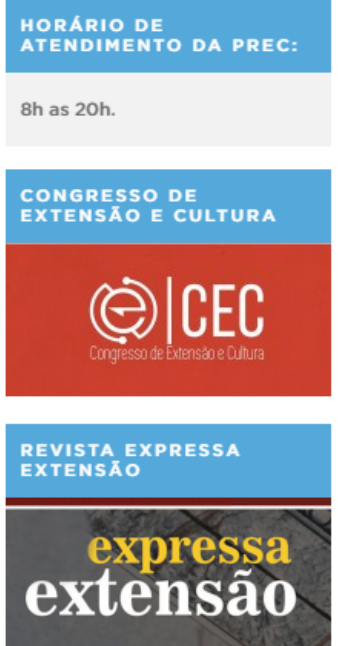

6 As orientações sobre acessibilidade nos sítios governamentais estão disponível no seguinte endereço: http:// emag.governoeletronico.gov.br/ 
Para avaliar se o site é acessível, atualmente existem avaliadores online que testam a acessibilidade do site e indicam os pontos que devem ser melhorados. São exemplos:

AccessMonitor - WCAG1.0/2.0 (português)

http://www.acessibilidade.gov.pt/

FAE - Functional Accessibility Evaluator WCAG2.0/section508 http://fae20.cita.illinois.edu/

Total Validator - WCAG1.0/2.0/Section508

http://www.totalvalidator.com/ 


\section{RECURSOS DE TECNOLOGIA ASSISTIVA}

A seguir serão colocados recursos de tecnologia assistiva que permitem o acesso de fruição, participação, produção e expressão da pessoa com deficiência nos ambientes museais.

Cabe ressaltar que estes recursos são fundamentais para o acesso cultural da pessoa com deficiência, mas também beneficiam um público amplo, justamente por possibilitarem a todos os visitantes experiências multissensoriais.

$\mathrm{Na}$ sequência discutem-se algumas tecnologias assistivas relacionadas às dimensões da acessibilidade.

\subsection{Acessibilidade Arquitetônica}

A normativa que prevê a acessibilidade arquitetônica é a NBR 9050. Nela é possível encontrar os padrões de medidas para ambientes, adaptações e mobiliários. Neste manual serão apontados alguns itens da normativa de acessibilidade.

Entretanto, ressalta-se a importância da consulta do documento na íntegra. É importante destacar que além de pensar o ambiente do museu em si, faz-se necessário planejar e desenvolver um percurso acessível desde os meios de transporte (paradas de ônibus, táxis, metrô, ...) até a entrada do museu. Também como a disponibilização de Vaga de Estacionamento Privativas tanto para Pessoas com deficiência como para Idosos, em frente à entrada do Museu. 


\subsubsection{Acessibilidade arquitetônica para pessoa com Deficiência Visual}

Para deslocamento com autonomia e independência, pessoas com deficiência visual precisam de piso podotátil para se locomover. Existem duas categorias:

- Piso direcional: é aquele que mostra o caminho a ser percorrido pela pessoa com deficiência visual. É composto pelo piso com três linhas paralelas.

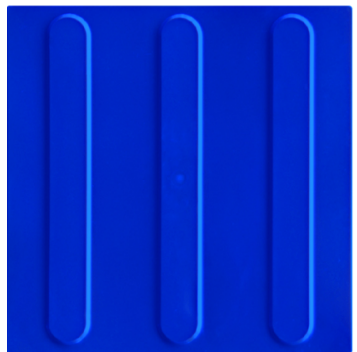

Figura 6: Piso direcional. Fonte: Google Imagens

- Piso alerta: como o próprio nome diz, é o piso que indica que a pessoa deve estar alerta, pois há um obstáculo ou troca da rota do piso direcional

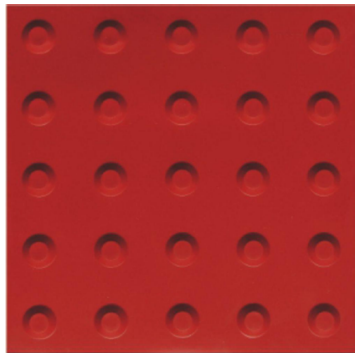

Figura 7: Piso alerta. Fonte: Google Imagens

Cabe destacar que para a colocação do piso de forma correta devem ser seguidas as indicações da NBR9050, que além de normatizar os parâmetros métricos, também orienta para que os pisos possuam cores contrastantes entre eles.

Caso não seja possível a colocação do piso podotátil, faz-se necessário que o museu tenha uma segunda opção para que a locomoção da pessoa com deficiência visual seja autônoma e independente. 
Um exemplo é o Museu da Comunidade Concelhia da Batalha, em Portugal, que ao invés de colocar o piso podotátil, colocou um trilho contínuo no percurso da exposição onde a pessoa com deficiência visual poderia identificar com a bengala e seguir o percurso de forma autônoma e independente. Neste trilho há duas sinalizações diferentes durante o percurso: para identificar onde há o recurso de audioguia, há uma esfera acoplada ao trilho; para indicar onde estão as peças para tocar, há um triângulo apontando para a direção onde a peça se encontra. Ambas as sinalizações são facilmente identificadas pelo contato com a bengala.

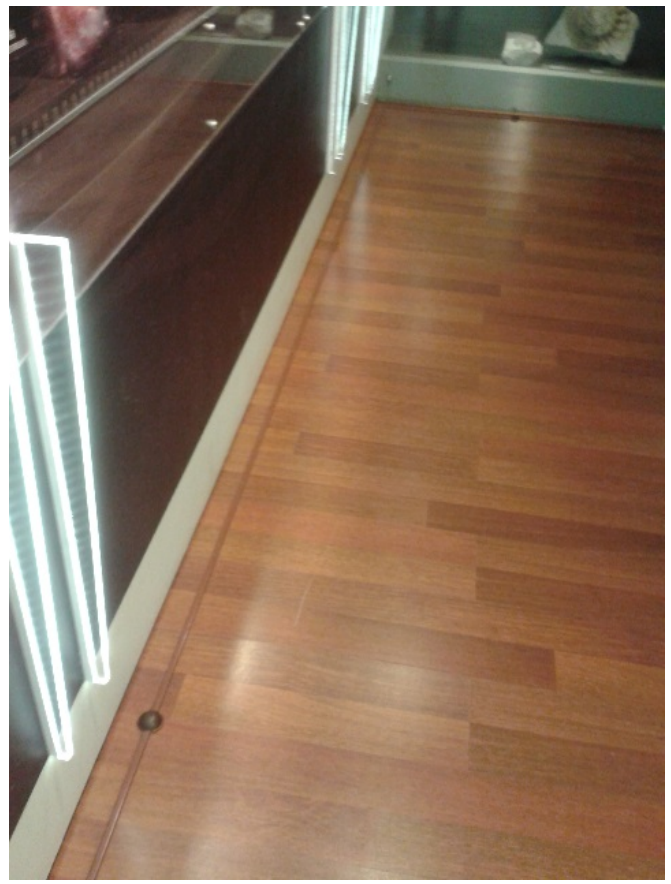

Figura 8: Trilho podotátil no Museu da Comunidade Concelhia da Batalha. Fonte: Acervo da autora

Em escadas deve-se tomar o cuidado de colocar a fita antiderrapante com cores contrastantes em cada degrau e o corrimão com duas alturas.

O corrimão com às duas alturas é importante por duas situações: a primeira diz respeito às crianças e às pessoas com baixa estatura; a segunda é para proteção e segurança da pessoa que está utilizando o corrimão.

Ainda em relação à acessibilidade arquitetônica, recomenda-se que as cores 
utilizadas nas exposições sigam um padrão de contrastes para auxiliar a pessoa com baixa visão.

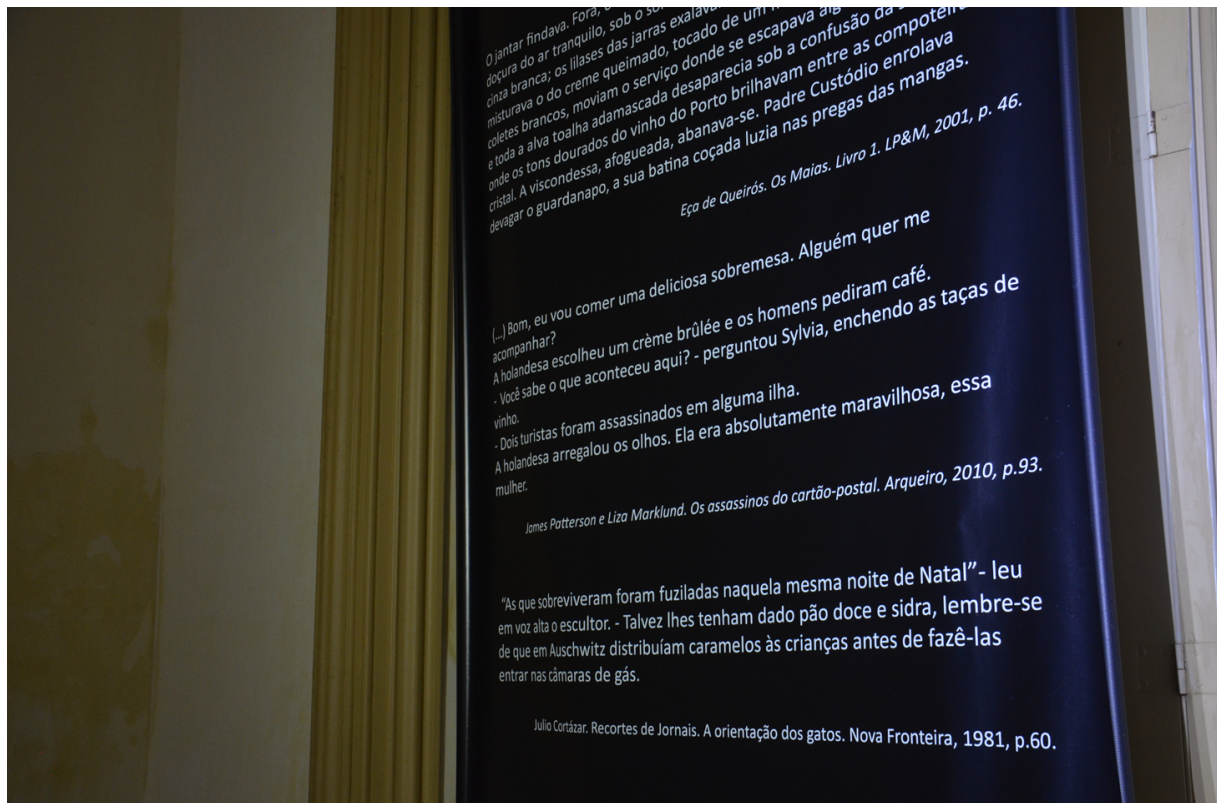

Figura 9: Painel com cores contrastantes no Museu do Doce. Fonte: Acervo da Rede de Museus da UFPel.

\subsubsection{Acessibilidade arquitetônica para surdos e pessoas com deficiência auditiva}

Em geral, a surdez e a deficiência auditiva não enfrentam barreiras arquitetônicas que as impeça de se locomoverem nos espaços.

\subsubsection{Acessibilidade arquitetônica para pessoas com mobilidade reduzida e idosos}

Entende-se que esta parcela da população, na sua grande maioria, utiliza recursos de tecnologia assistiva para se locomoverem, tais como: bengalas, cadeiras de rodas e andadores.

Em geral, precisam que o espaço de circulação seja amplo, que as aberturas/ portas tenham no mínimo $90 \mathrm{~cm}$ (considerando apenas a passagem da pessoa em 
cadeira de rodas) e o ambiente possua lugares para descanso.

Caso não seja possível colocar um banco fixo neste espaço, faz-se necessário que o museu possua bancos móveis à disposição de seus visitantes.

Quando houver vitrines, o museu deve seguir a normativa para que a altura desta esteja confortável para o visitante com deficiência.

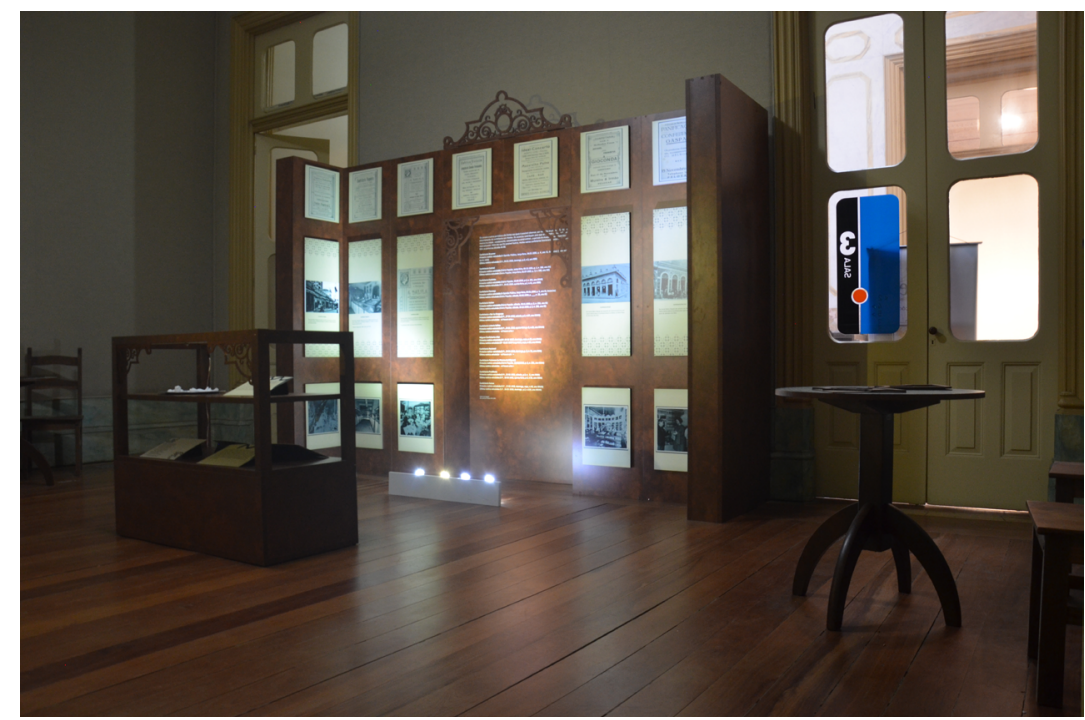

Figura 10: Vitrine rebaixada no Museu do Doce. Fonte: Acervo da Rede de Museus da UFPel.

No caso do museu possuir mais de um andar é imprescindível que o ambiente possua um elevador. Entretanto, quando não for possível é preciso que a equipe pense a curadoria da exposição de forma a utilizar somente o piso térreo.

Não sendo possível, a equipe deve estar preparada para auxiliar a pessoa com mobilidade reduzida a ultrapassar a barreira arquitetônica com um plano B.

Havendo desníveis entre salas, ou na entrada/saída do museu, será necessária a colocação de uma rampa ${ }^{7}$ e/ou sinalização indicativa.

O museu deverá conter, ainda, estacionamento reservado para pessoa com deficiência, próximo à entrada e, no mínimo, um banheiro adaptado 8 .

7 Para colocação da rampa de forma funcional, verifique a NBR9050.

8 Respeitando a NBR9050. 


\section{Banheiros}

Os banheiros devem estar acessíveis para todos os visitantes, porém faz-se necessário que haja banheiros adaptados. Abaixo se destacam alguns pontos importantes:

1 - O ideal é que as portas sejam de correr, porque às vezes não há espaço suficiente para a passagem de cadeira de rodas;

2 - As torneiras devem funcionar por sensor ou ser acionadas por alavanca;

3 - Verificar a altura do dispenser de sabonete e do secador de mãos;

4 - Cordão de comunicação em casos de emergência, com um sistema de alarme;

5 - Usar cores contrastantes entre acessórios, pisos e paredes;

6 - Optar por lixeiras sem pedal;

7 - O vaso sanitário não deverá possuir recorte, porque o mesmo oferece perigo para pessoas sem mobilidade de membros inferiores;

8 - Fraldários devem estar em banheiros de família. Caso não seja possível, procurar colocar tanto no banheiro feminino, quanto no masculino. Porque é importante salientar que não são somente os bebês que utilizam fraldas, há pessoas com deficiência que também fazem o uso, assim, faz-se necessário planejar um ambiente onde seja possível trocar fraldas de crianças, adolescentes e adultos.

\subsection{Acessibilidade Atitudinal}

No que tange aos recursos de tecnologia assistiva em acessibilidade atitudinal, é necessário que a equipe do museu possua formação em acessibilidade e em mediação acessível. Sugere-se que a formação da equipe abranja as seguintes temáticas:

1 - Acessibilidade, Inclusão e Diversidade;

2 - Deficiência Visual;

3 - Surdez;

4 - Deficiência Motora/ Física;

5 - Deficiência Intelectual;

6 - Transtorno do Espectro Autista e Altas Habilidades. 
A mediação acessível caracteriza-se como um recurso de tecnologia assistiva onde o mediador é responsável por transmitir o discurso expositivo através dos recursos de tecnologia assistiva do museu para que o visitante tenha o seu acesso garantido. Assim, visitantes, recursos de tecnologia assistiva e discurso expositivo formam uma tríade da mediação acessível, como mostra a Figura 11.

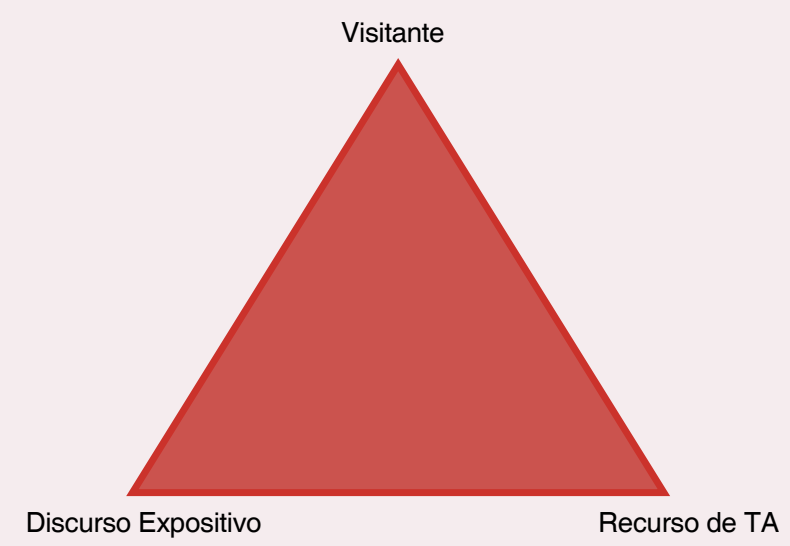

Figura 11: Tríade da Mediação Acessível. Fonte: Acervo da autora

Para que a mediação acessível ocorra é preciso que o mediador:

1 - Conheça os tipos de deficiência;

2 - Faça uma avaliação detalhada dos recursos disponíveis no museu;

3 - Verifique se o site do museu é acessível;

4 - Pesquise e implemente novos recursos que ampliem o acesso;

5 - Nunca esqueça que a acessibilidade atitudinal é o que fará a grande diferença no processo de acessibilidade e inclusão do público no museu! 


\subsection{Acessibilidade Comunicacional}

A acessibilidade comunicacional nos museus se caracteriza como os recursos de tecnologia assistiva que permitem o discurso expositivo ser traduzido para formatos alternativos, com o objetivo de garantir o acesso do conteúdo da exposição por parte das pessoas com deficiência.

\subsubsection{Pessoa com Deficiência visual}

Por estarem privadas do sentido da visão, quando as exposições possuem recursos essencialmente visuais, as pessoas com esta característica acabam sendo excluídas. Assim, para garantir o acesso ao conteúdo são necessários os seguintes recursos:

1 - Audiodescrição de imagens e ambiente;

2 - Maquetes e esquemas táteis;

3 - Peças originais (ou réplicas) disponíveis ao toque;

4 - Materiais de apoio (catálogos, folhas de sala ${ }^{9}$ ) em braile;

5 - Material de apoio (catálogos, folhas de sala) impresso em fonte ampliada (tamanho 28, alinhamento à esquerda, espaçamento 1,5)

9 Material disponível em cada sala que explica a exposição. 


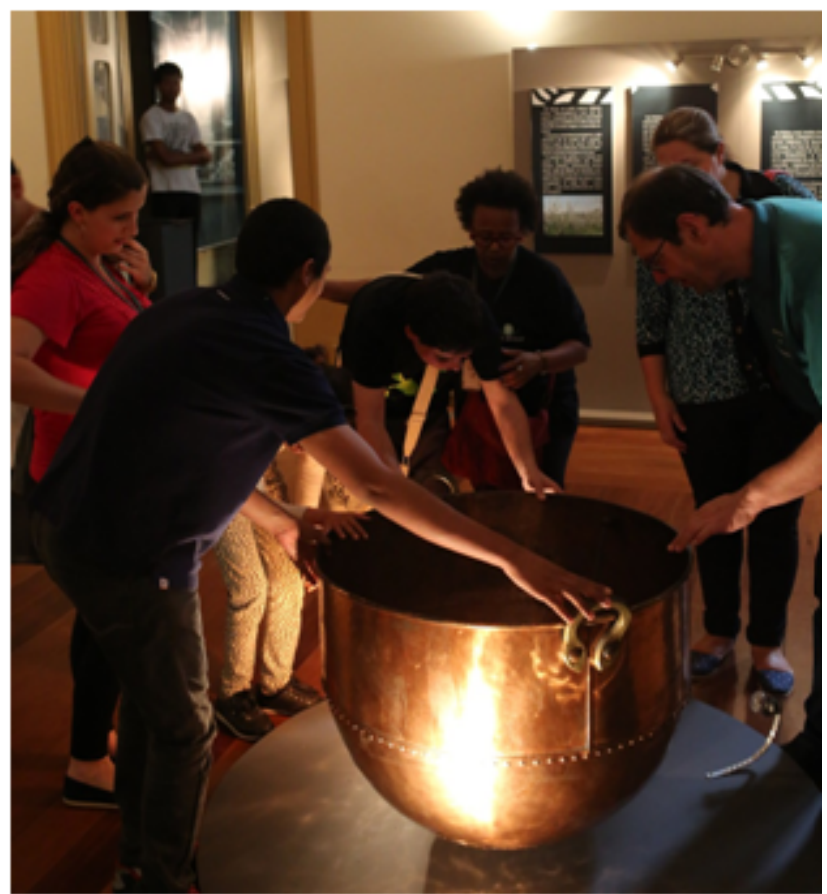

Figura 12: Visitantes tocam no tacho, peça original à disposição no Museu do Doce. Fonte: Moisés Vasconcellos

\subsubsection{Surdos e pessoas com deficiência auditiva}

Uma vez que as pessoas surdas são nativas da Língua Brasileira de Sinais, faz-se necessário que as informações em língua portuguesa estejam traduzidas para libras.

Esta tradução pode ocorrer de duas formas:

- Gravada: onde é necessário disponibilizar um dispositivo de vídeoguia.

- Ao vivo: com um tradutor/intérprete de Libras para fazer a mediação acessível.

No caso de pessoas com deficiência auditiva, não há necessidade de recursos de acessibilidade comunicacional nos materiais expostos no museu, salvo os casos de recursos audiovisuais. Estes serão tratados no item sobre acessibilidade instrumental. 


\subsubsection{Pessoas com mobilidade reduzida / Idosos}

Em geral, pessoas com mobilidade reduzida não enfrentam barreiras comunicacionais que as impeça de entender o conteúdo da exposição.

Nem toda pessoa idosa precisará de auxílio de tecnologia assistiva para entender o conteúdo de uma exposição. Entretanto, em alguns casos, é indicado que o recurso comunicacional seja feito através de um mediador acessível ${ }^{10}$.

\subsubsection{Pessoa com Deficiência Intelectual}

Para que pessoas com deficiência intelectual consigam absorver o conteúdo de uma exposição, a melhor estratégia é através da mediação acessível. Porém, esta mediação deverá considerar que conceitos abstratos são de difícil compreensão, e por este motivo, devem ser transmitidos visualmente ou através do toque.

São exemplos de recursos de acessibilidade comunicacional para pessoas com deficiência intelectual:

1 - Materiais com linguagem simples;

2 - Materiais em sistema pictográfico de comunicação ${ }^{11}$;

3 - Encenações teatrais;

4 - Imagens;

5 - Peças originais ou réplicas disponíveis ao toque.

10 Ver mediação acessível no glossário.

11 Ver Sistema Pictográfico de Comunicação no glossário. 


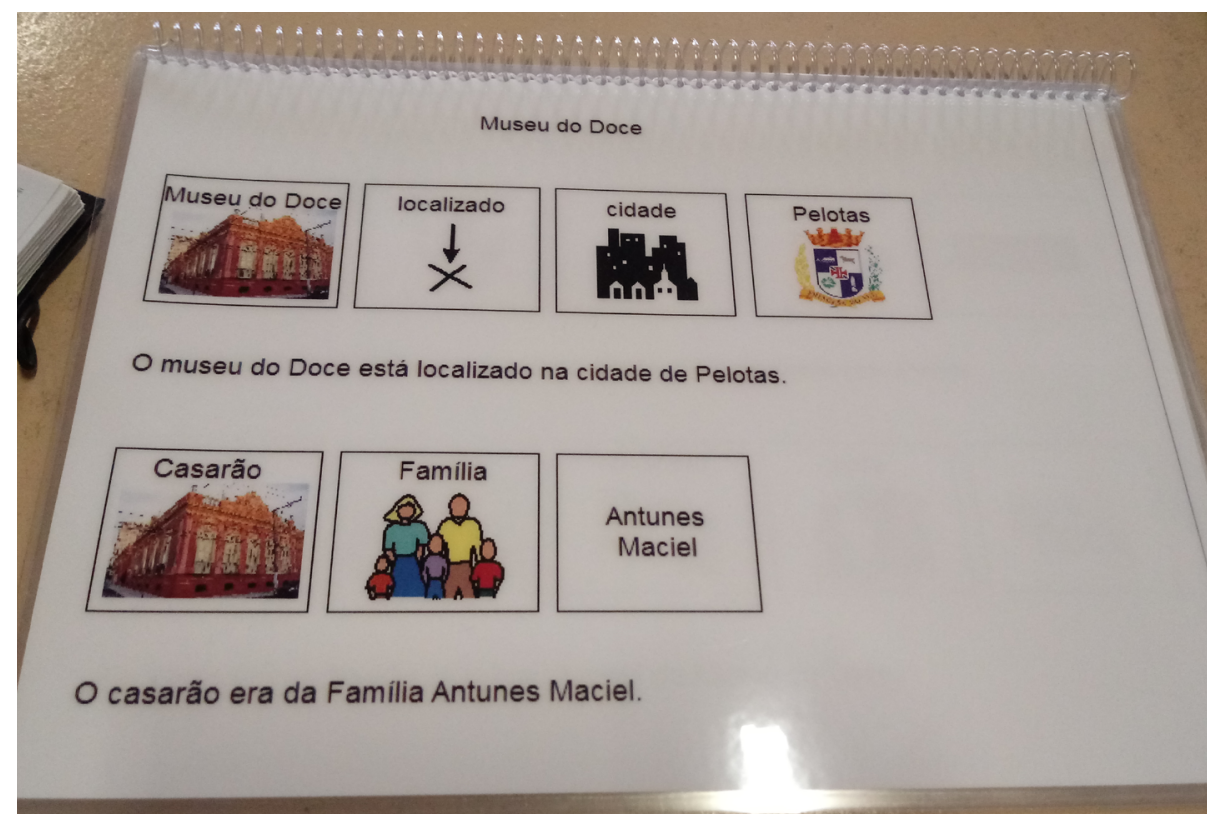

Figura 13: Recurso de Comunicação Alternativa no Museu do Doce - Sistema Pictográfico de Comunicação. Fonte: Acervo da autora

\subsubsection{Pessoas com Autismo}

Nem toda pessoa com autismo precisará de auxílio de tecnologia assistiva para entender o conteúdo de uma exposição. Entretanto, quando necessário, podem ser utilizados os mesmos recursos indicados para pessoas com deficiência intelectual.

No caso da mediação acessível é importante atentar para o fato de que algumas pessoas com autismo possuem Transtorno de Processamento Sensorial, e que isso pode gerar desconfortos com relação a ruídos, toque e muitos estímulos visuais.

\subsubsection{Pessoas com Altas Habilidades}

Pessoas com altas habilidades não necessitam de auxílio de tecnologia assistiva para entender o conteúdo de uma exposição. Entretanto, cabe ao museu disponibilizar material para pesquisas, caso o visitante deseje mais informações sobre determinado conteúdo. 


\subsection{Acessibilidade Instrumental}

Instrumentos utilizados para a mediação de acessibilidade comunicacional entre visitante e museu são considerados recursos de tecnologia assistiva relacionados à acessibilidade instrumental.

\subsubsection{Instrumentos para pessoa com deficiência visual}

São exemplos de instrumentos que efetivam o acesso da pessoa com deficiência em museus:

1 - Audioguia de uso intuitivo ${ }^{12}$

2 - Maquetes e esquemas táteis;

3 - Recursos audiovisuais com audiodescrição;

4 - Recursos tecnológicos, tais como: tablets, smartphones, etc.

\subsubsection{Instrumentos para surdos / pessoas com deficiência auditiva}

Os principais instrumentos para a pessoa surda em um museu são os vídeos ${ }^{13}$, que devem estar em Libras (quando se tratar de um vídeoguia) ou conter a janela de Libras.

Para contemplar pessoas ensurdecidas ou com deficiência auditiva, os recursos audiovisuais devem possuir legendagem.

\subsubsection{Instrumentos para pessoas com mobilidade reduzida / idosos}

Os recursos de acessibilidade instrumental para pessoas com mobilidade reduzida, no geral, são aqueles já listados na acessibilidade arquitetônica.

Entretanto, para algumas pessoas idosas, o principal instrumento será o

12 Neste sentido, o uso intuitivo diz respeito ao menor número possível de ações que o visitante deve fazer para acessar a informação. Por exemplo, um audioguia que tenha apenas um botão para acionar o seu funcionamento.

130 Guia Orientador de produção Audiovisual do Ministério da Cultura apresenta as normativas que devem ser seguidas para a produção destes recursos. Disponível em: https://www.camara.gov.br/internet/agencia/pdf/ guia_audiovisuais.pdf 
mediador. Mas estes também se beneficiam dos seguintes recursos:

1 - Audioguia com uso intuitivo;

2 - Audiovisuais com legendas ${ }^{14}$;

3 - Maquetes e esquemas táteis.

\subsubsection{Instrumentos para pessoas com deficiência intelectual}

A acessibilidade instrumental para pessoas com esta característica se dá através dos seguintes recursos:

1 - Material em sistema pictográfico de comunicação;

2 - Mediação acessível;

3 - Materiais de apoio essencialmente visuais;

4 - Maquetes e esquemas táteis.

\subsubsection{Instrumentos para pessoas com autismo}

Nem toda pessoa com autismo precisará de auxílio de acessibilidade instrumental. Entretanto, quando necessário, podem-se utilizar os mesmos recursos indicados para pessoas com deficiência intelectual.

\subsubsection{Instrumentos para pessoas com altas habilidades}

Pessoas com Altas Habilidades podem desejar mais informações sobre determinado conteúdo. Assim, o recurso que possibilitará a ela este acesso poderá provir de:

1 - Acervos que podem ser disponibilizados para consulta local;

2 - Site com conteúdo e links com informações mais detalhadas.

\subsection{Acessibilidade Metodológica}

São exemplos de métodos que abrangem todos os públicos: mediação acessível e sensorial, jogos, teatro, músicas, entre outros.

14 As legendas devem estar de acordo com a normativa de acessibilidade ao audiovisual. 


\section{ALGUNS RECURSOS DE TECNOLOGIA ASSISTIVA}

\subsection{Audiodescrição}

A audiodescrição (AD) é um recurso de tradução intersemiótica onde tudo que é essencialmente visual é traduzido para palavras. É uma técnica que exige formação para ser realizada de forma funcional, ou seja, que não confunda a pessoa com deficiência visual ao invés de auxiliá-la. Por isso a importância de contratar um profissional capacitado para fazer o trabalho.

A AD é produzida por uma equipe composta por roteirista, revisor e consultor. Existem três tipos de audiodescrição: gravada, ao vivo e escrita. Para cada uma delas, há especificidades. Nos museus ela servirá tanto para as obras quanto para o ambiente.

\subsection{Braile}

O braile é um sistema universal composto por 63 combinações de 6 pontos e uma cela em branco. Foi criado por Louis Braille, em 1837, com base em um código militar criado por Charles Barbier, que auxiliava os soldados franceses a se comunicarem nos campos de batalha durante a noite. Com as combinações do braile é possível escrever o alfabeto, números e até mesmo partituras. É importante destacar que mesmo com o avanço das tecnologias e dos leitores de tela, o sistema é amplamente utilizado até os dias de hoje e carrega consigo a identidade cultural de pessoas cegas. 


\subsection{Linguagem Simples}

É um recurso para auxiliar na compreensão da leitura e que exige formação específica para que seja realizado de forma efetiva. Deve obedecer aos princípios e fundamentos da técnica, por isso exige a contratação de um profissional capacitado.

Linguagem simples não pode ser confundida como uma escrita feita para crianças, porque a mesma deverá seguir o rigor da escrita principal e transmitir as mesmas informações sem infantilizá-las ou descaracterizá-las. 


\section{ACESSIBILIDADE A TEXTOS ESCRITOS}

Alinhamento: deverá ser sempre à esquerda. O alinhamento justificado faz do texto "um grande bloco" e serve como obstáculo para leitura e a atenção dos visitantes.

Pessoas com déficit de aprendizagem têm maior dificuldade para ler um texto justificado pelo fato do espaçamento entre as palavras ficarem irregular. Bem como, há alguns pesquisadores que já demonstraram que museus onde há textos muito extensos e em alinhamento justificado acabam não sendo interessantes, e desta maneira, os visitantes acabem optando por não ler as informações.

Espaçamento entre linhas: dê preferência para a utilização do espaçamento entre linhas de 1,5.

Fontes: fontes com serifa ${ }^{15}$ podem confundir pessoas com déficit de aprendizagem ou com baixa visão. Por isso, procure usar sempre fontes sem serifa em seus materiais como, por exemplo, Helvética, Arial, Verdana, etc. Também é importante procurar não ultrapassar o limite de setenta caracteres por linha, usar sentenças curtas e apresentar o conteúdo principal já nas primeiras linhas, cuidar para que as palavras não fiquem divididas ao final de cada linha e optar pelo negrito ao invés do itálico. 


\section{EXEMPLOS DE ATIVIDADES NO SETOR EDUCATIVO DO MUSEU}

O espaço dedicado ao Setor Educativo do museu deverá contar com recursos humanos que estejam capacitados para receber públicos diversificados, tendo sido treinados para realização de mediação acessível, conforme já citado anteriormente.

A mediação acessível consiste no acompanhamento do visitante na exposição, de modo a conduzi-lo e apresentar os recursos de acessibilidade disponibilizados no museu. Além disto, é preceito básico que o mediador acessível domine as técnicas de orientação e mobilidade para pessoas cegas, audiodescrição, caso seja necessário fazê-la ao vivo, e princípios ligados à acessibilidade atitudinal. Também é relevante ter na equipe do museu um mediador surdo ou um tradutor/ intérprete de Libras para fazer a mediação para visitantes surdos.

Ainda, cabe ao setor educativo, fazer ações de sensibilização com os visitantes e com a equipe do museu. Para tal, quando houver marcações de visitas, devem-se apresentar as opções de atividades que podem ser realizadas no museu.

A seguir são listadas algumas sugestões de atividades de sensibilização voltadas para a diversidade. 


\subsection{Sensibilização para a Deficiência Visual}

\subsubsection{Pintura às escuras}

Análise da Atividade

Objetivo: Sensibilizar para a importância da audiodescrição em museus.

Materiais necessários: Folhas A4, lápis, vendas.

Espaço: Uma sala onde os visitantes possam sentar.

Riscos: Esta atividade não oferece riscos.

Idade recomendada: Não há limite, funciona bem com todos os públicos.

Esta atividade consiste em desenhar, com os olhos vendados, uma peça do acervo do museu. Para tal, os visitantes devem ser colocados em um local onde tenham espaço para desenhar. Cada um deve ganhar uma folha em branco, um lápis e uma venda. Após todos vendarem os olhos, o mediador deverá fazer a áudiodescrição da peça escolhida, frase por frase, de modo que os visitantes possam ir desenhando aos poucos. Ao final da atividade, os participantes retiram as vendas e comparam o seu desenho à peça original. Após este momento, é papel do mediador acessível apresentar o recurso da audiodescrição como meio de inclusão cultural para pessoas com deficiência e ressaltar a importância deste em um museu.

\subsubsection{Percurso Sensorial}

Análise da Atividade

Objetivo: Sensibilizar para a importância de recursos sensoriais nos museus Materiais necessários: Vendas, tapete sensorial, pequenos alimentos para degustação, elementos que agucem o olfato, maquetes e/ou esquemas táteis, som. É importante que o visitante possa ficar de meias/descalço durante a atividade.

Espaço: Pode ser feito em uma sala separada, ou dentro da própria exposição (ligando os elementos a cada sala, por exemplo)

Riscos: Esta atividade não oferece riscos, desde que acompanhada pelo mediador acessível.

Idade recomendada: Não há limite, funciona bem com todos os públicos. 
Esta atividade consiste em separar o museu em estações dos sentidos. $\mathrm{Na}$ entrada, os visitantes recebem vendas e são orientados sobre a atividade. Ao chegarem ao hall, junto aos ladrilhos hidráulicos, pisam sobre um tapete sensorial com texturas diversas. Na segunda sala, ouvem o som de uma cozinha industrial, da fabricação de doces. Após o estímulo auditivo, aguça-se o paladar com a próxima estação, onde se deve proporcionar os visitantes pequenos elementos para reconhecimento através do paladar. Em seguida, elementos do casarão oito ficam disponíveis ao toque e a áudio-descrição. A última estação explora o sentido do olfato, onde os visitantes deverão reconhecer elementos das doçarias somente pelo cheiro. Para finalizar, visitantes tiram as vendas e o mediador deve evidenciar a importância de estímulos sensoriais, para além do sentido da visão, em museus para que as pessoas com deficiência visual, e não só, tenham experiências significativas nestes ambientes.

\subsubsection{Um Museu para Sentir}

Análise da Atividade

Objetivo: Gerar empatia e promover as pessoas com deficiência visual enquanto protagonistas e promotoras de acessibilidade cultural

Materiais necessários: Vendas, óculos que reproduzem tipos de baixa visão, mediadores cegos e/ou com baixa visão

Espaço: Exposição

Riscos: Esta atividade não oferece riscos, desde que acompanhada pelos mediadores.

Idade recomendada: Não há limite.

Esta atividade requer confirmação prévia de número de participantes.

Esta é uma visita para sentir e confiar no outro. Na entrada do museu, os visitantes devem receber vendas e/ou óculos que reproduzem tipos de baixa visão. Logo em seguida, devem ser divididos grupos para cada guia DV. A visita consiste no guia DV apresentar o museu através de sua visão e experiência. Para tal, poderse-á colocar algumas estações sensoriais no museu, para além dos recursos já ofertados pelo mesmo. Fica a critério da organização da visita. Caso sejam 
colocadas outras estações, sugere-se que estas sejam nos moldes da atividade do Percurso Sensorial, citada no item anterior. Ao final desta, guias e visitantes fazem uma conversa sobre a experiência. Ao mediador acessível (responsável pela organização da atividade), cabe finalizar esclarecendo dúvidas sobre a deficiência visual e o acesso aos museus.

\subsubsection{Caça ao Braile}

Análise da Atividade

Objetivo: Conhecer o Sistema Braile

Material necessário: Alfabeto braile impresso em tinta, pistas em braile, computador com/sem projetor, lápis e borrachas.

Espaço: Museu

Riscos: Esta atividade não oferece riscos, desde que seja acompanhada pelo mediador acessível.

Idade recomendada: Não há limite.

O mediador deve entregar aos participantes o material contendo lápis, borracha, alfabeto braile impresso em tinta e as pistas em braile. Antes de começar a atividade prática, é papel do mediador contextualizar a ação e explicar a história do braile e como ele funciona. A atividade é similar à caça ao tesouro. Devem ser distribuídas 10 pistas para cada participante/grupo. Para cada pista encontrada, o participante deverá recolher uma peça, obtendo ao final, 10. Porém, como as pistas estarão em braile, é preciso decodificar cada uma, por isso a importância da primeira etapa da atividade. Ao final da atividade cada grupo deverá ganhar uma lembrancinha pela participação e falar sobre a experiência de decodificação do braile. 


\subsection{Sensibilização para a Surdez}

\subsubsection{Mãos que falam}

Análise da Atividade

Objetivo: Sensibilizar para a importância de aprender Libras

Material necessário: Fichas com emoções, fichas com pequenas frases, fichas com imagens, fichas com imagens que contem uma história conhecida por todos.

Espaço: Museu

Riscos: Esta atividade não oferece riscos, desde que seja acompanhada pelo mediador acessível.

Idade recomendada: Não há limite.

Esta atividade consiste em dividir o museu em quatro estações. Participantes não devem comunicar-se utilizando a linguagem verbal e deverão ser separados por pequenos grupos. Cada grupo deverá ser identificado por um sinal da Língua de Sinais.Em cada estação deverá haver um desafio, onde cada participante, por vez, deverá retirar uma ficha e reproduzi-la para o grupo imitar.

Por exemplo:

Em uma estação, se distribuem oito fichas com diferentes sentimentos. Um participante escolhe uma ficha, olha-a sem mostrar para o resto do grupo, e deve reproduzi-la. O grupo, por conseguinte, imita-a também. Na próxima estação estarão frases simples. O procedimento é o mesmo da estação anterior. É importante destacar que mesmo que os participantes saibam Libras, não devem utilizá-la, pois o desafio desta atividade é comunicar-se. Ao final destas estações, deve-se juntar o grupo todo e, em roda, um a um, deve pegar uma ficha da história e tentar reproduzila. Quando todos terminarem, deverão falar que história acabaram de contar.

Em seguida, inicia-se uma conversa sobre a importância da Libras para os surdos e caso haja algum, ou algum intérprete, este deverá ensinar ao grupo alguns sinais básicos da língua. 


\subsection{Sensibilização para a Deficiência Intelectual}

Análise da Atividade

Objetivo: Conhecer um pouco sobre a deficiência intelectual

Material necessário: Um projetor e um computador com internet.

Espaço: Museu

Riscos: Esta atividade não oferece riscos, desde que seja acompanhada pelo mediador acessível.

Idade recomendada: Não há limite.

Para a sensibilização para a deficiência intelectual sugere-se apresentar o curtametragem “Cordas ou Por que Heloísa?”. 


\section{CONSIDERAÇÕES FINAIS}

É crescente a percepção da necessidade dos ambientes museais se adaptarem para incluir pessoas com deficiência em seus espaços. Inúmeros museus têm buscado novos profissionais, de diversas áreas, para ampliar as possibilidades de interação do ambiente com seus visitantes. Entretanto, o caminho a percorrer ainda é longo, e para quem trabalha com acessibilidade, é importante destacar que o trabalho nunca estará finalizado, pois carece de constante atualização.

Antes de iniciar o planejamento para desenvolver um museu inclusivo, fazse necessário uma avaliação prévia do ambiente e a identificação do público que o museu pretende receber. Assim, será possível ter um diagnóstico sobre quais recursos serão utilizados e quais profissionais deverão integrar a equipe ou serem contratados. Porém, nada disso será funcional se os profissionais não chamarem o público-alvo para consultoria e avaliação de seus materiais. Ou seja, se houver um piso podotátil, faz-se necessário chamar consultores cegos para testar, e no caso dos recursos não serem funcionais, o museu deverá respeitar os consultores e buscar aprimorá-los para melhor servir seus visitantes.

Acessibilizar um ambiente, como pode-se notar neste manual, é uma tarefa complexa, que demanda uma equipe multidisciplinar, uma vez que um museu pode ter barreiras físicas, sensoriais, intelectuais e atitudinais. Neste caso, o museu, ao invés de ser um agente em potencial de cultura e educação, será o agente incapacitante da pessoa, porque apenas apresentará limitações e entraves que não permitirão a participação e expressão da pessoa com deficiência. Deve-se considerar que as demandas da acessibilidade nem sempre serão onerosas ou de 
difícil implementação. Muitas vezes o principal é mudar comportamentos, atitudes e pré-conceitos em relação às pessoas com deficiência. Por isso a relevância de se fomentar formações em acessibilidade e inclusão para a equipe do museu.

É importante lembrar que se as deficiências são diversificadas, o ambiente também deverá proporcionar experiências múltiplas e significativas.

Atualmente vários autores da área da inclusão apontam a potencialidade do museu ofertar visitas com mediações sensoriais, pois são enriquecedoras para todos os públicos.

Pensar em "todos" significa entender que a sociedade é plural e que não há uma homogeneidade na população. É entender que as diferenças nos potencializam e nos enriquecem enquanto seres humanos.

Garantir a acessibilidade cultural para pessoas com deficiência é garantir a dignidade humana, a possibilidade de escolha em apreciar determinada obra, de tocar em uma peça original que é importante para aquela comunidade e de ampliar o seu repertório de conhecimentos, ou seja, a pessoa com deficiência ser considerada uma cidadã e ser tratada com as mesmas oportunidades de usufruir junto com as demais.

Esperamos que este manual auxilie nesta trajetória rumo à inclusão! 


\section{GLOSSÁRIO}

Acessibilidade - garantia de acesso para pessoas com deficiência em igualdade de oportunidades com os demais.

Audiodescrição (AD) - recurso de tecnologia assistiva e de tradução intersemiótica.

Audioguia - instrumento utilizado para explicar informações aos visitantes.

Autonomia - capacidade da pessoa tomar uma decisão para a realização de uma ação/atividade. É ligada à vontade, ao desejo.

Braile - sistema de escrita e leitura para pessoas com deficiência visual.

Desenho universal - desenvolvimento de produtos, equipamentos e ambientes que pressupõe o uso por grande parte da população, respeitando à diversidade humana.

Esquema tátil - recurso de tecnologia assistiva. É uma reprodução, em escala reduzida, que permite o toque e entendimento de objetos, fotografias e etc.

Inclusão - pressupõe o respeito às diferenças. É onde todas as pessoas têm acesso à determinada ação/objeto sem estar separado por ser pessoa com deficiência. 
Independência - capacidade física, intelectual, sensorial e biopsicossocial para a realização de uma ação/atividade. É ligada às habilidades do corpo humano.

Integração - integra a pessoa com deficiência, mas de forma segregada ou separada dos demais.

Libras - Língua Brasileira de Sinais.

Maquetes - reprodução em escala reduzida de determinado objeto.

Mediador - profissional que media a comunicação entre o museu e o visitante.

Mediação acessível - mediação que tem por objetivo proporcionar a interlocução entre ambiente, recursos de tecnologia assistiva e visitantes.

Pessoa com deficiência - termo utilizado para caracterizar pessoas que têm alguma limitação de longo prazo de caráter sensorial, cognitivo, mental ou físico.

Piso alerta - piso que identifica obstáculos e perigos para pessoas com deficiência visual.

Piso direcional - piso que direciona o caminho para pessoas com deficiência visual.

Piso podotátil - piso utilizado para guiar e alertar pessoas com deficiência visual.

Plegia - perda ou diminuição significativa de força muscular. Pode ser monoplegia, onde há perda de força de apenas um membro. Paraplegia, perda da força nos membros inferiores. Hemiplegia, onde há perda de força em um lado do corpo e Tetraplegia, onde há perda da força nos quatro membros e no tronco.

Programa de acessibilidade - documento norteador sobre a acessibilidade no museu.

Sistema pictográfico de comunicação - recursos de comunicação alternativa e aumentativa para pessoas com deficiência intelectual e/ou problemas na fala.

Tecnologia assistiva (TA) - recursos que auxiliam na fruição das pessoas com deficiências nos mais diversos contextos. 


\section{LISTA DE FIGURAS}

Figura 1 Espaço amplo e mobiliário rebaixado no Museu do Doce ....................................... 28

Figura 2 Espaço amplo e mobiliário rebaixado no Museu do Doce ........................................2 29

Figura 3 Esquema tátil que auxilia o entendimento da fotografia no Memorial do Anglo ............. 30

Figura 4 Aparelho de mp3 utilizado como instrumento para audiodescrição ............................... 31

Figura 5 Tela principal do site da Pró-Reitoria de Extensão e Cultura - UFPel ......................... 34

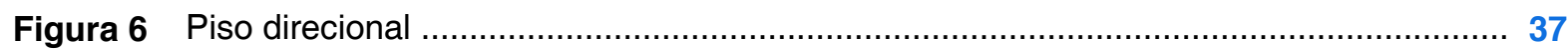

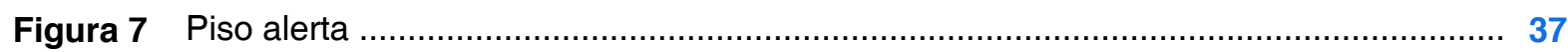

Figura 8 Trilho podotátil no Museu da Comunidade Concelhia da Batalha ............................... 38

Figura 9 Painel com cores contrastantes no Museu do Doce ........................................... 39

Figura 10 Vitrine rebaixada no Museu do Doce ............................................................ 40

Figura 11 Tríade da Mediação Acessível .................................................................. 42

Figura 12 Visitantes tocam no tacho, peça original à disposição no Museu do Doce ................... 44

Figura 13 Recurso de Comunicação Alternativa no Museu do Doce .......................................46 


\section{BIBLIOGRAFIA RECOMENDADA}

ARANHA, Maria Salete. Paradigmas da relação da sociedade com as pessoas com deficiência. Revista do Ministério Público do Trabalho, v. 11, n. 21 mar. 2001. p. 160-173. Disponível em: <http://www.adion.com.br/mznews/data/ paradigmas.pdf>. Acesso em: 11 jun. 2018.

ASSOCIAÇÃO BRASILEIRA DE NORMAS TÉCNICAS. NBR 9050: acessibilidade a edificações, mobiliário, espaços e equipamentos urbanos. Rio de Janeiro: ABNT, 2004.

BRASIL. Lei 11.904. Estatuto dos museus. Disponível em: <http://www.planalto. gov.br/ccivil_03/_Ato2007-2010/2009/Lei/L11904.htm>. Acesso em: 11 set. 2018

BRASIL. Lei 13.146. Lei Brasileira de Inclusão - Estatuto da Pessoa com Deficiência. Disponível em: <http://www.planalto.gov.br/ccivil_03/_Ato20152018/2015/Lei/L13146.htm>. Acesso em: 27 set. 2018

CAMBIAGHI, Silvana. Desenho universal: métodos e técnicas para arquitetos e urbanistas. São Paulo: Senac, 2007.

CARDOSO, Eduardo; CUTY, Jenifer (Orgs.). Acessibilidade em ambientes culturais: relatos de experiências. Porto Alegre: Marcavisual, 2014.

COHEN, Regina; DUARTE, Cristiane; BRASILEIRO, Alice. Acessibilidade a museus. Brasília: MinC/IBRAM, 2012. 
IPHAN. Portaria normativa $\mathrm{n}^{\circ} \mathbf{1}$ de $\mathbf{5}$ de julho de 2006. Dispõe sobre a elaboração do Plano Museológico dos museus do Instituto do Patrimônio Histórico e Artístico Nacional e dá outras providências.

MOTTA, Lívia M. V. M.; ROMEU FILHO, P. (orgs) Audiodescrição: transformando imagens em palavras. São Paulo: Secretaria dos Direitos da Pessoa com Deficiência do Estado de São Paulo, 2010.

POLÍTICA nacional de museus. Disponível em: <https://www.museus.gov.br/ wp-content/uploads/2010/01/politica_nacional_museus.pdf>. Acesso em: 22 set. 2018.

RESOURCE: The Council for Museums, Archives and Libraries. Acessibilidade/ Resource: The Council for Museums, Archives and Libraries; [tradução Maurício O. Santos e Patrícia Souza]. - São Paulo: Editora da Universidade de São Paulo: Vitae, 2005. 120p.

SALASAR, D. N; SANTOS, E. A. dos; MICHELON, F. F. Acessibilidade em museus: o terapeuta ocupacional como mediador de acessibilidade cultural para pessoas com deficiência. 134f. Trabalho de Conclusão de Curso (Graduação em Terapia Ocupacional) - Faculdade de Medicina, Universidade Federal de Pelotas, 2017.

SARRAF, Viviane Panelli. Acessibilidade em espaços culturais: mediação e comunicação sensorial. São Paulo: EDUC; FAPESP, 2015.

SASSAKI, Romeu Kazumi. Inclusão: acessibilidade no lazer, trabalho e educação. Revista Nacional de Reabilitação (Reação). São Paulo, v. 12, p. 10 -16, mar./ abr. 2009.

TOJAL, Amanda Pinto da Fonseca. Políticas públicas culturais de inclusão de públicos especiais em museus. Tese de Doutorado. São Paulo: Universidade de São Paulo. 2007. 
